\title{
Serotonin Neuron Transplants Exacerbate L-DOPA- Induced Dyskinesias in a Rat Model of Parkinson's Disease
}

\author{
Thomas Carlsson, ${ }^{1}$ Manolo Carta, ${ }^{1,2}$ Christian Winkler, ${ }^{3}$ Anders Björklund, ${ }^{2}$ and Deniz Kirik ${ }^{1}$ \\ ${ }^{1}$ CNS Disease Modeling Unit and ${ }^{2}$ Neurobiology Unit, Department of Experimental Medical Science, Lund University, 22184 Lund, Sweden, and \\ ${ }^{3}$ Department of Neurology, Hannover Medical School, 30625 Hannover, Germany
}

\begin{abstract}
Clinical trials in patients with Parkinson's disease have shown that transplants of fetal mesencephalic dopamine neurons can form a new functional innervation of the host striatum, but the clinical benefits have been highly variable: some patients have shown substantial recovery in motor function, whereas others have shown no improvement and even a worsening in the 3,4-dihydroxyphenyl-L-alanine (L-DOPA)-induced dyskinetic side effects. Differences in the composition of the grafted cell preparation may contribute to these discrepancies. In particular, the number of serotonin neurons contained in the graft can vary greatly depending on the dissection of the fetal tissue. Importantly, serotonin neurons have the ability to store and release dopamine, formed from exogenously administered L-DOPA. Here, we have evaluated the effect of transplants containing serotonin neurons, or a mixture of dopamine and serotonin neurons, on L-DOPA-induced dyskinesias in 6-hydroxydopamine-lesioned animals. As expected, dopamine neuron-rich grafts induced functional recovery, accompanied by a $60 \%$ reduction in L-DOPA-induced dyskinesia that developed gradually over the first 10 weeks. Rats with serotonin-rich grafts with few dopamine neurons, in contrast, showed a progressive worsening of their L-DOPA-induced dyskinesias over time, and no functional improvement. The antidyskinetic effect of dopamine-rich grafts was independent of the number of serotonin neurons present. We conclude that serotonin neurons in the grafts are likely to have a detrimental effect on L-DOPA-induced dyskinesias in cases in which the grafts contain no or few dopamine neurons.
\end{abstract}

Key words: 5-hydroxytryptamine; 6-hydroxydopamine; cell grafting; dopamine; levodopa; ventral mesenchephalon

\section{Introduction}

Restoration of function by intrastriatal transplants of fetal mesencephalic dopamine (DA) neurons has been explored in clinical trials in patients with advanced Parkinson's disease (PD). The results have been highly variable, with some patients showing a substantial recovery in motor function, and others showing little or no improvement. In open-label trials, a significant reduction in peak dose dyskinesias ("on" time with dyskinesias) has been reported in some patients, whereas in others the 3,4dihydroxyphenyl-L-alanine (L-DOPA)-induced dyskinesias have been unaffected or increased (Widner et al., 1992; Defer et al., 1996; Hagell et al., 1999; Hauser et al., 1999; Brundin et al., 2000). These discrepancies have been suggested, at least in part, to be attributable to the differences in dissection and preparation of the fetal tissue, in which tissue clumps, tissue stripes, or single-cell suspensions have been used (Winkler et al., 2005). It is known that transplanted ventral mesencephalic (VM) tissue, apart from DA neurons, contains also other neuronal cell types, including serotonin neurons, and variations in tissue dissection are likely to

Received May 7, 2007; revised June 9, 2007; accepted June 13, 2007.

This work was supported by the Parkinson Disease Foundation (M.C.), the Michael J. Fox Foundation, and the Swedish Research Council (04X-3874 to A.B.; 33IT-15331 and 33X-14552 to D.K.). We thank Anneli Josefsson, Ulla Jarl, and Bengt Mattsson for their technical support.

Correspondence should be addressed to Deniz Kirik, Wallenberg Neuroscience Center, BMC A11, 22184 Lund, Sweden. E-mail: deniz.kirik@med.lu.se.

DOI:10.1523/JNEUROSCI.2079-07.2007

Copyright $\odot 2007$ Society for Neuroscience $\quad$ 0270-6474/07/278011-12\$15.00/0 result in varying numbers of different cell types in the graft cell preparation.

The serotonin neurons are of particular interest in this regard, because they have the capacity to convert L-DOPA to DA, store the newly formed DA in vesicles, and release it in an activitydependent manner ( $\mathrm{Ng}$ et al., 1970, 1971; Hollister et al., 1979; Arai et al., 1994, 1995; Maeda et al., 2005). In dopaminergic terminals DA release is controlled via DA reuptake by the DA transporter (DAT) and $\mathrm{D}_{2}$ autoreceptor feedback control. However, in the absence of any autoregulatory control mechanisms, DA released from serotonin terminals is likely to show excessive swings that may be particularly prone to induce dyskinesias. In support of this hypothesis, in a recent study we showed that L-DOPA administration in rats with complete lesions of the ascending DA pathway led to $\sim 50 \%$ reduction in tissue serotonin levels in the striatum. L-DOPA-induced dyskinesias in these animals could be almost completely blocked by either lesions of the serotonin system or blockade of serotonin (5-HT) neuron activity by a combination of 5- $\mathrm{HT}_{1 \mathrm{~A}}$ plus $5-\mathrm{HT}_{1 \mathrm{~B}}$ receptor agonists (Carta et al., 2007). These findings suggested that L-DOPA-derived DA, released as a "false transmitter" from serotonin terminals, is the main trigger of dyskinesia in the rat PD model. It is likely, therefore, that the presence of serotonin neurons in the grafts will not only take part in the conversion of peripherally administered L-DOPA to DA, but also play a role in the induction and maintenance of the dyskinetic side effects.

In the present study, we investigated the functional effects of 
grafted brainstem serotonin neurons, transplanted alone or in combination with VM DA neurons, in 6-hydroxydopamine (6OHDA)-lesioned rats with already established L-DOPA-induced dyskinesias. The results show that serotonin neuron grafts induce severe L-DOPA-induced dyskinesias, whereas DA neuron-rich grafts, regardless of the number of serotonin cells included, are effective in reversing these side effects. The reduction in L-DOPAinduced dyskinesia seen in animals with DA neuron-rich grafts was accompanied by a significant improvement in motor behavior, as well as a normalization of the lesion-induced DA receptor supersensitivity in response to the DA receptor agonist apomorphine. None of these improvements was observed in the grafts containing serotonin neurons only.

\section{Materials and Methods \\ Animals}

A total of 120 adult female Sprague Dawley rats was obtained from B\&K Universal (Stockholm, Sweden). The animals were 8 weeks old and weighed 225-250 $\mathrm{g}$ at the beginning of the study. They were housed at the animal facility of the Biomedical Center at Lund University under standardized conditions with $12 \mathrm{~h}$ light/dark cycle and ad libitum access to food and water. All procedures used in this study were regulated by ethical permits obtained from the Ethical Committee for use of laboratory animals in the Lund-Malmo Region.

\section{Experimental design and behavioral tests}

The sequence of surgeries and tests is summarized in Figure $1 \mathrm{~A}$. In the beginning of the study, all animals received a unilateral 6-OHDA lesion in the medial forebrain bundle (MFB). To ensure complete lesion of the nigrostriatal DA pathway, the animals were screened by amphetamineinduced rotation at a dose of $2.5 \mathrm{mg} / \mathrm{kg}$. Seventy-eight rats exhibited more than five full-body turns per minute, ipsilateral to the DA-lesioned side. Sixty-nine of these were treated with daily injections of L-DOPA at 6 $\mathrm{mg} / \mathrm{kg}$ (with $15 \mathrm{mg} / \mathrm{kg}$ benserazide hydrochloride) for $28 \mathrm{~d}$ to induce abnormal involuntary movements (AIMs) (induction phase), equivalent to peak dose dyskinesias seen in PD patients. At the end of this period, 56 animals exhibited stable AIMs. Forty-one animals were finally included in the study and allocated into four balanced groups. Twelve weeks after the lesion, three of the four groups were transplanted with three different types of fetal tissue single-cell suspension grafts (see Fig. $1 \mathrm{~B}$ ). One group received cells from the anterior segment of the VM containing high numbers of dopaminergic and low numbers of serotonergic neuroblasts (referred to as DA narrow; $n=10$ ). The second group received equal numbers of cells from a wider dissection in the VM, including higher numbers of serotonergic neuroblasts (referred to as DA wide; $n=10$ ). The third group of animals was grafted with tissue dissected from the dorsal pontine raphe region (referred to as 5 -HT; $n=10$ ), which contained high numbers of serotonergic cells but no or very few dopaminergic neuroblasts. The fourth group of dyskinetic rats were sham-operated and included as control [Les-Ctrl (L-DOPA), $n=10$ ]. Finally, a group of L-DOPA-naive-lesioned animals were included as a second control group [Les-Ctrl (Drug-Naive), $n=6$ ]

One week after transplantation surgery, the L-DOPA treatment was reinstated at the same dose, but twice weekly (maintenance phase), in the four L-DOPA treatment groups, and the Les-Ctrl (Drug-Naive) group continued to receive vehicle injections on the same days. The magnitude and frequency of AIMs were scored at 2, 4, 6, 10, 13, 16, 18 (after $3 \mathrm{mg} / \mathrm{kg}$ L-DOPA), and 21 weeks. At 22 weeks, L-DOPA-induced dyskinesia was evaluated after coadministration of a combination of $0.05 \mathrm{mg} / \mathrm{kg}$ 8-hydroxy-2-(di- $n$-propylamino)tetralin (8-OH-DPAT) and $1.0 \mathrm{mg} / \mathrm{kg}$ 3-(1,2,5,6-tetrahydro-4-pyridyl)-5-propoxypyrrolo[3,2-b]pyridine (CP-94253), which are 5- $\mathrm{HT}_{1 \mathrm{~A}}$ and $5-\mathrm{HT}_{1 \mathrm{~B}}$ receptor agonists [obtained from Tocris (Bristol, UK)]. At 19 weeks after grafting, L-DOPAinduced rotation was conducted using $3 \mathrm{mg} / \mathrm{kg}$. At 23 and 24 weeks apomorphine-induced dyskinesias and rotation were evaluated at a dose of $0.05 \mathrm{mg} / \mathrm{kg}$. Spontaneous forelimb use was assessed OFF-L-DOPA in the cylinder test at 3 weeks after the 6-OHDA lesion and at 22 weeks after the transplantation. Finally, at 27 weeks dyskinesias were evaluated after an intraperitoneal injection of $1.5 \mathrm{mg} / \mathrm{kg}$ D-amphetamine. The animals were killed by an overdose of pentobarbital and perfused with $4 \%$ paraformaldehyde (PFA) for histological analysis at 28 weeks after grafting.

\section{6-OHDA lesion}

The surgery was performed under injectable anesthesia (20:1 mixture of fentanyl and Dormitor, intraperitoneal; Apoteksbolaget, Stockholm, Sweden). Briefly, the animals were mounted in a stereotaxic frame (Stoelting, Wood Dale, IL) and $14 \mu \mathrm{g}$ of 6-OHDA (calculated as free base; Sigma-Aldrich, Stockholm, Sweden) was injected at a concentration of $3.5 \mu \mathrm{g} / \mu \mathrm{l}$ (in $0.2 \mathrm{mg} / \mathrm{ml}$ ascorbate in saline) at one site in the MFB using a Hamilton syringe. The anterior-posterior (AP) and mediolateral (ML) coordinates were -4.4 and $-1.2 \mathrm{~mm}$ relative to bregma. The injection was made at a dorsoventral (DV) position of $-7.8 \mathrm{~mm}$ from the surface of the dura, and the tooth bar was set to $-2.4 \mathrm{~mm}$. The toxin was injected at a rate of $1 \mu \mathrm{l} / \mathrm{min}$, and the syringe was kept in place for an additional 3 min to allow diffusion before it was slowly retracted.

\section{Cell preparation and transplantation surgery}

The fetal cells were dissected from embryonic day 14 rat embryos, as illustrated in Figure $1 B$. To obtain a cell suspension rich in DA neuroblasts but with as few serotonin cells as possible, the rostral cut was placed so as to include part of the caudal diencephalon. Then, a midline cut was performed through the tectum, and the tissue was folded open so that the inside of the neural tube was facing upward. The rhombencephalic isthmus was identified and care was taken to perform the caudal cut at $\sim 1-1.5 \mathrm{~mm}$ rostral to the isthmus. Thus, this approach yielded a dissected tissue piece containing approximately one-half of the midbrain (see Fig. $1 B$, DA-narrow group) [i.e., it was narrower compared with the commonly used standard approach as described by Dunnett and Bjorklund (1992)]. Finally, a dorsal cut was performed through the midbrain to limit the tissue to the ventral third of the midbrain piece. The standard VM cell suspension that contained both DA and serotonin neuroblasts was performed as described previously (DA-wide group) (Nikkhah et al., 1994; Winkler et al., 1999; Kirik et al., 2001; Georgievska et al., 2004; Carlsson et al., 2006). In this dissection, the caudal cut was performed slightly caudal to the rhombencephalic isthmus to include the entire VM and most rostral part of the pontine raphe region in the final tissue piece processed for transplantation (see Fig. $1 B$ ). In the third group (see Fig. $1 B, 5-\mathrm{HT}$ ), a more caudal tissue piece, at the level of pontine raphe was dissected by first performing a dorsal midline cut through the tectum. The rhombencephalic isthmus and the pontine flexure were then identified and the pontine raphe region was dissected by cutting out a rectangular block of $0.5 \mathrm{~mm}$ on either side of the ventral midline between these two landmarks. The most rostral part was excluded from the dissection to minimize the inclusion of DA neuroblasts in the preparation.

The dissected tissue pieces were processed by incubation in DMEM, containing $0.1 \%$ trypsin and $0.05 \%$ DNase, for $30 \mathrm{~min}$ at $37^{\circ} \mathrm{C}$, mechanically dissociated into single-cell suspensions, and concentrated by centrifugation at $500 \mathrm{rpm}$ for $5 \mathrm{~min}$. The total amount of cells in the cell suspensions was counted by trypan blue viability staining using a counting chamber. Finally, volume of the suspensions was adjusted so that the final concentration was 130,000 cells $/ \mu$ in each case. The viabilities of the cell suspensions were 96,98 , and $99 \%$ for the DA-wide, DA-narrow, and 5-HT cell preparations, respectively.

All transplantation surgery was performed under fentanyl-Dormitor anesthesia as detailed above. The rats were mounted in the stereotaxic frame with a $5 \mu \mathrm{l}$ Hamilton syringe fitted with a glass capillary (outer diameter, $60-80 \mu \mathrm{m})$. The DA-narrow, the DA-wide, and the 5-HT groups received injection of 130,000 cells through one needle penetration at $\mathrm{AP}$ of $+0.2 \mathrm{~mm}$ and $\mathrm{ML}$ of $-3.5 \mathrm{~mm}$. The tooth bar was set to 0.0 , and two deposits of $0.5 \mu \mathrm{l}$ each were placed at the DV coordinates -5.0 and $-4.0 \mathrm{~mm}$, relative to the dura. After injection, the syringe was kept in place for an additional $3 \mathrm{~min}$ before it was retracted slowly. At the end of the transplantation session, the viability of all cell suspensions was estimated to be $>95 \%$.

\section{Behavioral analysis}

Drug-induced rotation. Rotational behavior induced by amphetamine $(2.5 \mathrm{mg} / \mathrm{kg})$, apomorphine $(0.05 \mathrm{mg} / \mathrm{kg})$, or L-DOPA $(3 \mathrm{mg} / \mathrm{kg})$ was 
monitored in rotometer bowls, and the animals' right and left $90^{\circ}$ body turns were recorded using a computerized hardware and a specialized software (AccuScan Instrument, Columbus, $\mathrm{OH}$ ). In all cases, the testing sessions were performed over $90 \mathrm{~min}$, and the data are expressed as total net full-body turns per minute. A positive value indicates rotations ipsilateral to the lesion side. Amphetamine-induced rotation was recorded at 2 weeks after the 6-OHDA lesion to evaluate the extension of the lesion, and at 8 weeks after transplantation to confirm the presence of surviving functional DA neurons in the grafts. All 78 6-OHDA-lesioned rats included in the study displayed more than five full-body turns per minute in the pretransplantation test. L-DOPA-induced rotation was recorded at 19 weeks using a dose of $3 \mathrm{mg} / \mathrm{kg}$ L-DOPA ( $+15 \mathrm{mg} / \mathrm{kg}$ benserazide). Apomorphine-induced rotation was recorded at 24 weeks in the automated rotometer, after an injection of $0.05 \mathrm{mg} / \mathrm{kg}$ subcutaneous dose.

Cylinder test. The cylinder test was performed, at 3 weeks after the 6-OHDA lesion and at 22 weeks after the transplantation, to score the animals' spontaneous forelimb use (Schallert and Tillerson, 1999; Kirik et al., 2001). The animals were individually placed in a 20 -cm-diameter glass cylinder, in which they move freely and explore while they were video filmed. The weight-shifting movements of the forepaws in contact with the wall of the glass cylinder were scored from the recorded material by an observer blinded to the animal's identity. A total of 20 touches using either the left or right forepaw with the wall of the cylinder was noted for each animal, and the data are presented as the use of the left (impaired) paw in percentage of total touches. In normal controls with equal use of the two paws, the score is thus $50 \%$.

L-DOPA-induced dyskinesia. Stable AIMs, resembling peak dose dyskinesias in patients, were induced in the animals by daily injections of 6 $\mathrm{mg} / \mathrm{kg}$ L-DOPA (Research Organics, Cleveland, $\mathrm{OH}$ ) in combination with $15 \mathrm{mg} / \mathrm{kg}$ benserazide hydrochloride (a peripheral decarboxylase inhibitor; Sigma) for $28 \mathrm{~d}$. The L-DOPA and the benserazide was mixed and dissolved in physiological saline and administered to each rat as a subcutaneous injection. This route of administration has been adopted after the findings of Lindgren et al. (2007) suggesting that the subcutaneous injections gave more consistent and reliable L-DOPA response compared with the intraperitoneal route. The dyskinetic animals were allocated to one of the four experimental groups (see above), and kept on a maintenance regimen of twice-weekly L-DOPA injections for an additional 29 weeks (Lee et al., 2000). AIM scores were assessed at the end of the induction period, and at 2, 4, 6, 10,13,16, 18, and 21 weeks after transplantation. The 18 week test was performed with $3 \mathrm{mg} / \mathrm{kg} \mathrm{L}$-DOPA, whereas all other tests were performed at the $6 \mathrm{mg} / \mathrm{kg}$ dose. The pregrafting score is the average of three consecutive tests, $3 \mathrm{~d}$ apart, whereas the postgrafting scores are the means of two test sessions, $4 \mathrm{~d}$ apart. In addition, at 22 weeks after grafting, the L-DOPA-induced dyskinesias were evaluated after injection of $0.05 \mathrm{mg} / \mathrm{kg} 8-\mathrm{OH}-\mathrm{DPAT}$ (a $5-\mathrm{HT}_{1 \mathrm{~A}}$ receptor agonist), in combination with $1.0 \mathrm{mg} / \mathrm{kg}$ CP-94253 (a 5- $\mathrm{HT}_{1 \mathrm{~B}}$ receptor agonist). The agonists were administered subcutaneously $10 \mathrm{~min}$ before $6 \mathrm{mg} / \mathrm{kg}$ L-DOPA.

AIMs were evaluated according to rat dyskinesia scale as described by Lee and colleagues with minor modifications (Lee et al., 2000; Winkler et al., 2002; Carlsson et al., 2006). Briefly, the animals were individually placed in transparent plastic cages without any sawdust and scored every $20 \mathrm{~min}$ for at least $3 \mathrm{~h}$ and until no AIMs were observed. The severity of the dyskinetic behaviors was assessed using scores of $0-4$ as follows: 0 , absent; 1 , occasional (i.e., present during $<50 \%$ of the observation time); 1.5 , present $50 \%$ of the observation time; 2 , frequent (i.e., present during $>50 \%$ of the observation time); 2.5 , present most of the time with very short duration of non-dyskinetic episodes; 3 , continuous, but interruptible by repeated sensory stimuli (e.g., sudden noise, opening of the cage lid); 3.5, continuous, but inconsistently interrupted by repeated sensory stimuli; 4 , continuous, not interrupted by repeated sensory stimuli. The scores were given in four subtypes according to topographic distribution as forelimb, orolingual, axial, and locomotive behaviors. The forelimb and orolingual behaviors are essentially seen as hyperkinetic movements, whereas the axial subtype is predominately dystonic. Enhanced manifestation of normal behaviors such as grooming, gnawing, rearing, and sniffing was not included in the rating. Integrated AIM scores were calculated as the area under the curve over the whole observation time.
Apomorphine- and amphetamine-induced dyskinesia tests. Dyskinesias induced by apomorphine $(0.05 \mathrm{mg} / \mathrm{kg}$; Sigma) were assessed at 23 weeks after grafting. The AIMs were recorded every $10 \mathrm{~min}$ for $90 \mathrm{~min}$, using the same rating scale as for L-DOPA-induced dyskinesias. Graft-induced AIMs were evaluated at 27 weeks after grafting after an injection of 1.5 $\mathrm{mg} / \mathrm{kg}$ D-amphetamine as described previously (Carlsson et al., 2006; Lane et al., 2006). The test was performed $7 \mathrm{~d}$ after the last L-DOPA injection to eliminate the risk for drug interference. AIMs were scored every $20 \mathrm{~min}$ for $6 \mathrm{~h}$ using the same rating scale as above. The data are presented as integrated AIM score as the area under the curve for the whole observation period.

\section{Histological analysis}

At 28 weeks after grafting, the animals were deeply anesthetized by an overdose of sodium pentobarbital (Apoteksbolaget) and transcardial perfusion with $50 \mathrm{ml}$ of physiological saline, followed by $250 \mathrm{ml}$ of freshly prepared ice-cold 4\% PFA in $0.1 \mathrm{~m}$ phosphate buffer, $\mathrm{pH}$ 7.4. The brains were removed and postfixed in the same fixative for additional $2-3 \mathrm{~h}$, and transferred into $25 \%$ sucrose for cryoprotection for at least $24 \mathrm{~h}$. The brains were cut using a semiautomated freezing slide-microtome (Microm HM 450) at $35 \mu \mathrm{m}$, divided into six series, and stored in antifreeze solution [0.5 M sodium phosphate buffer $\left(\mathrm{NaH}_{2} \mathrm{PO}_{4} / \mathrm{Na}_{2} \mathrm{HPO}_{4}\right)$ in $30 \%$ glycerol and $30 \%$ ethylenglycol in MillQ water] at $-20^{\circ} \mathrm{C}$ until further processing.

Immunohistochemistry. All staining procedures started with rinsing the free-floating sections in potassium-phosphate buffer (KPBS). Endogenous peroxidase activity was quenched by incubating the sections for 10 min in $3 \% \mathrm{H}_{2} \mathrm{O}_{2}$ and $10 \%$ methanol in KPBS. This step was followed by $1 \mathrm{~h}$ preincubation in $5 \%$ normal serum containing $0.25 \%$ Triton $\mathrm{X}-100$ in KPBS, and then by an incubation using the appropriate primary antibody in the same mixture of serum and Triton X-100 as follows: mouse anti-tyrosine hydroxylase (TH), MAB318, 1:2000; mouse anti-serotonin transporter (SERT), MAB1564, 1:1000 (Chemicon, Temecula, CA); and rabbit anti-serotonin, 1:10,000 (Immunostar, Hudson, WI). Incubations with the first two antibodies were allowed to proceed overnight at room temperature, whereas the third one was for $48 \mathrm{~h}$ at $4^{\circ} \mathrm{C}$. The second day of the staining procedure started with $1 \mathrm{~h}$ incubation in the appropriate biotinylated secondary antibodies [horse anti-mouse BA2001 for TH and SERT; goat anti-rabbit BA1000 for serotonin staining (Vector Laboratories, Burlingame, CA)] followed by a $1 \mathrm{~h}$ incubation with avidin-biotin peroxidase solution (ABC Elite; Vector Laboratories), and finally 3,3'diaminobenzidine and $0.01 \% \mathrm{H}_{2} \mathrm{O}_{2}$ were used to develop the color reaction. For SERT staining, nickel ammonium sulfate $(2.5 \mathrm{mg} / \mathrm{ml})$ was used to intensify the staining. The sections were mounted on chrom-alumcoated glass slides, dehydrated in ascending alcohol solutions, and cleared in xylene before they were coverslipped with Depex.

Stereological estimations of TH-and serotonin-positive cell numbers. The $\mathrm{TH}$ - and serotonin-positive cells were counted by the Computer Assisted Stereological Toolbox (CAST) module in VIS software (Visiopharm, Hørsholm, Denmark) using a $60 \times$ magnification oil lens with a numerical aperture of 1.40. Briefly, the grafts in the striatum were delineated, and a counting frame was randomly placed on the first counting area and moved systematically over the entire inclusion area on each section (Kirik et al., 2001). The sectioning frequency of specimens in each series (one in six) yielded 6-11 sections throughout the graft core. The penetration of the $\mathrm{TH}$ and serotonin antibodies were determined by registering the depth for each counted cell that appeared in focus within the counting frame. This analysis revealed the fact that the middle $4-5 \mu \mathrm{m}$ of the section thickness was poorly stained using both $\mathrm{TH}$ and serotonin antibodies (Torres et al., 2006). The counted volume therefore excluded this proportion of the sections with incomplete staining. Estimation of the total numbers of cells was conducted according to the optical fractionator principle (West, 1999). Coefficient of error attributable to the sampling was calculated according to Gundersen and Jensen (1987). Errors $\leq 0.1$ were accepted.

Striatal TH- and SERT-positive fiber density measurements. To determine the graft-derived fiber density in the striatum, the mean optical intensity was measured from the TH- and SERT-positive stained sections. Images were captured by a digital camera (ProgRes C14; Jenoptik, 

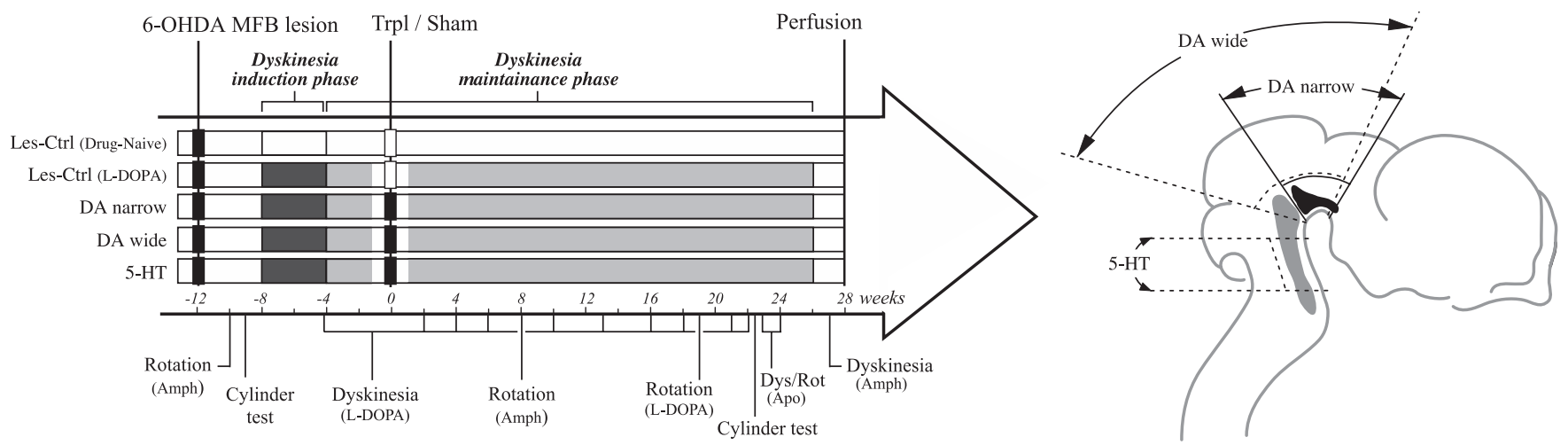

Figure 1. Experimental design and fetal tissue dissection. $\boldsymbol{A}$, Rats with complete 6-0HDA lesions of the MFB (inclusion criteria, $>5$ full-body turns per minute in the amphetamine test) were allocated to four groups balanced on the basis of their L-DOPA-induced dyskinesia scores (after 4 weeks of daily L-DOPA injections in the induction phase), as described in Materials and Methods, and received grafts of VM DA neurons with different rations of serotonin neurons (DA narrow, $n=10$; DA wide, $n=10$ ) or serotonin neurons alone (derived from the pontine raphe region; 5 -HT graft, $n=10$ ). The dissection used is displayed in $\boldsymbol{B}$ (for additional details, see Materials and Methods). A fourth group was sham-operated and kept as lesion controls [Les-Ctrl (L-DOPA), $n=10]$, and an additional group received neither graft nor L-DOPA and was kept as drug-naive controls [Les-Ctrl (Drug-Naive), $n=6$ ]. The animals were behaviorally tested over 28 weeks, during which time a maintenance regimen of twice-weekly L-DOPA injections was used (maintenance phase). L-DOPA-induced dyskinesias were evaluated at the end of the induction phase, and at 2, 4, 6, 10, 13, 16, 18, 21, and 22 weeks after the transplantation. For all tests, except at 18 weeks $(3 \mathrm{mg} / \mathrm{kg}), 6 \mathrm{mg} / \mathrm{kg} \mathrm{L-DOPA}$ (with $15 \mathrm{mg} / \mathrm{kg}$ benserazide) was used. In the last test, at 22 weeks, the L-DOPA-induced dyskinesias was evaluated under the influence of the $5-\mathrm{HT}_{1 \mathrm{~A}}$ receptor agonist, 8-OH-DPAT, and the 5- $\mathrm{HT}_{1 \mathrm{~B}}$ receptor agonist, $\mathrm{CP}-94253$, in combination. At 19 weeks, $\mathrm{L}-\mathrm{DOPA}$-induced rotation was assessed in rotometer bowls, and at 23-24 weeks, apomorphine-induced dyskinesia and rotation were evaluated. Amphetamine-induced rotation (to evaluate surviving DA grafts) and dyskinesias were monitored at 8 and 27 weeks after grafting. Finally, the animals were killed, and brains were fixed by PFA perfusion for histological analysis. The schematic drawing in $\boldsymbol{B}$, showing landmarks used for the dissection from embryonic day 14 rat embryos, is modified from Dunnett and Bjorklund (1992).

Jena, Germany) on a constant light illumination table and analyzed using the ImageJ software platform, version 1.34S for Mac OSX (National Institutes of Health; http://rsb.info.nih.gov/ij/). The measurements were conducted from seven coronal levels corresponding to the following coordinates: $\mathrm{AP},+1.6,+1.0,+0.2,-0.3,-0.9,-1.4$, and -2.1 (in millimeters), relative to bregma according to the atlas of Paxinos and Watson (2005). The entire striatum was delineated by the lateral ventricle medially, corpus callosum dorsally, and the external capsule laterally. A horizontal line connecting the ventral end of the ventricle via the anterior commissure to the external capsule constituted the ventral border. At levels where cell bodies were identified, the area of the graft core was excluded from the delineation. In sections 1 and 2, the rostrodorsolateral region ( $\mathrm{Rdl}$ ) was delineated by an oblique line passing through the striatum, and in sections 3 and 4 the caudal-lateral region $(\mathrm{Cl})$ was delineated by a vertical line dividing the striatum in the middle (illustrated in Figs. $4 A$ and $5 A$ ). Nonspecific background was determined by readings made from the corpus callosum, because this white matter tract did not contain any TH- or SERT-positive fibers. The data are expressed as optical density in percentage of the control side. Average densities were calculated from all seven coronal sections for the whole striatum, sections 1 and 2 for $\mathrm{Rdl}$ region, and sections 3 and 4 for the $\mathrm{Cl}$ region.

\section{Statistical analysis}

Comparisons between groups were performed using one-way ANOVA or two-way factorial ANOVA, or two-way repeated-measures ANOVA with individual contrast comparisons where appropriate. Post hoc analyses were performed using either Dunnett's test or Tukey's honestly significant difference (HSD) analysis. Statistical significance was set at $p<$ 0.05 for all analyses and is reported in the respective figure legends. All statistical comparisons were performed using the JMP Statistical software, version 5.0.1.2 (SAS Institute, Cary, NC).

\section{Results}

The present study was designed to evaluate the effect of serotonin neuron-containing grafts in modulating L-DOPA-induced dyskinesia in the rat model of PD. For this purpose, all animals first received a 6-OHDA injection in the MFB to achieve a complete lesion of the nigrostriatal DA pathway (Fig. $1 \mathrm{~A}$ ). The animals fulfilling the inclusion criteria (more than five turns per minute in the amphetamine-induced rotation test) were subjected to daily injections of $6 \mathrm{mg} / \mathrm{kg} \mathrm{L}$-DOPA for 4 weeks to establish a stable dyskinetic response. The dyskinetic animals were then allocated to four balanced groups, from which three groups received transplants of fetal cells derived from the VM, known to be rich in DA neuroblasts with high or low numbers of serotonin cells included (DA-wide group, $n=10$; DA-narrow group, $n=$ $10)$, or from the pontine raphe region containing high numbers of serotonin cells but no or few DA neurons (5-HT group, $n=$ 10) (dissections as shown in Fig. $1 B$ ). The fourth group of L-DOPA-treated animals was sham-operated and received no graft [Les-Ctrl (L-DOPA), $n=10$ ]. An additional fifth group of 6-OHDA-lesioned rats received neither grafts nor L-DOPA and was included as drug-naive control group [Les-Ctrl (DrugNaive), $n=6$ ]. The animals were longitudinally tested for their behavioral response to L-DOPA and direct or indirect DA receptor agonists for a period of 28 weeks after grafting.

\section{Survival and fiber outgrowth from the graft}

Immunohistochemical staining for $\mathrm{TH}$ and serotonin revealed surviving grafts in all transplanted animals included in the study (Fig. 2). The TH-positive cells were abundant in both the DAwide and DA-narrow groups, with clusters of cell bodies located at the periphery of the graft, and provided abundant fiber innervation in the adjacent host striatum (Fig. $2 A, C$ ). In the DA-wide grafts, there was an enrichment of serotonin neurons compared with DA-narrow group (Fig. 2 B,D). The 5-HT group contained numerous serotonin-positive neurons with similar distribution, but lacked the DA neuron component (Fig. 2, compare E, F). The total cell numbers in the grafts were estimated by stereological analysis tools. This analysis confirmed the qualitative observations and showed high numbers of TH-positive cells (6732 \pm 837 ) with only $782 \pm 108$ serotonin-positive cells ( $\sim 9: 1$ ratio) in the DA-narrow group. As expected, in the 5-HT graft group, 


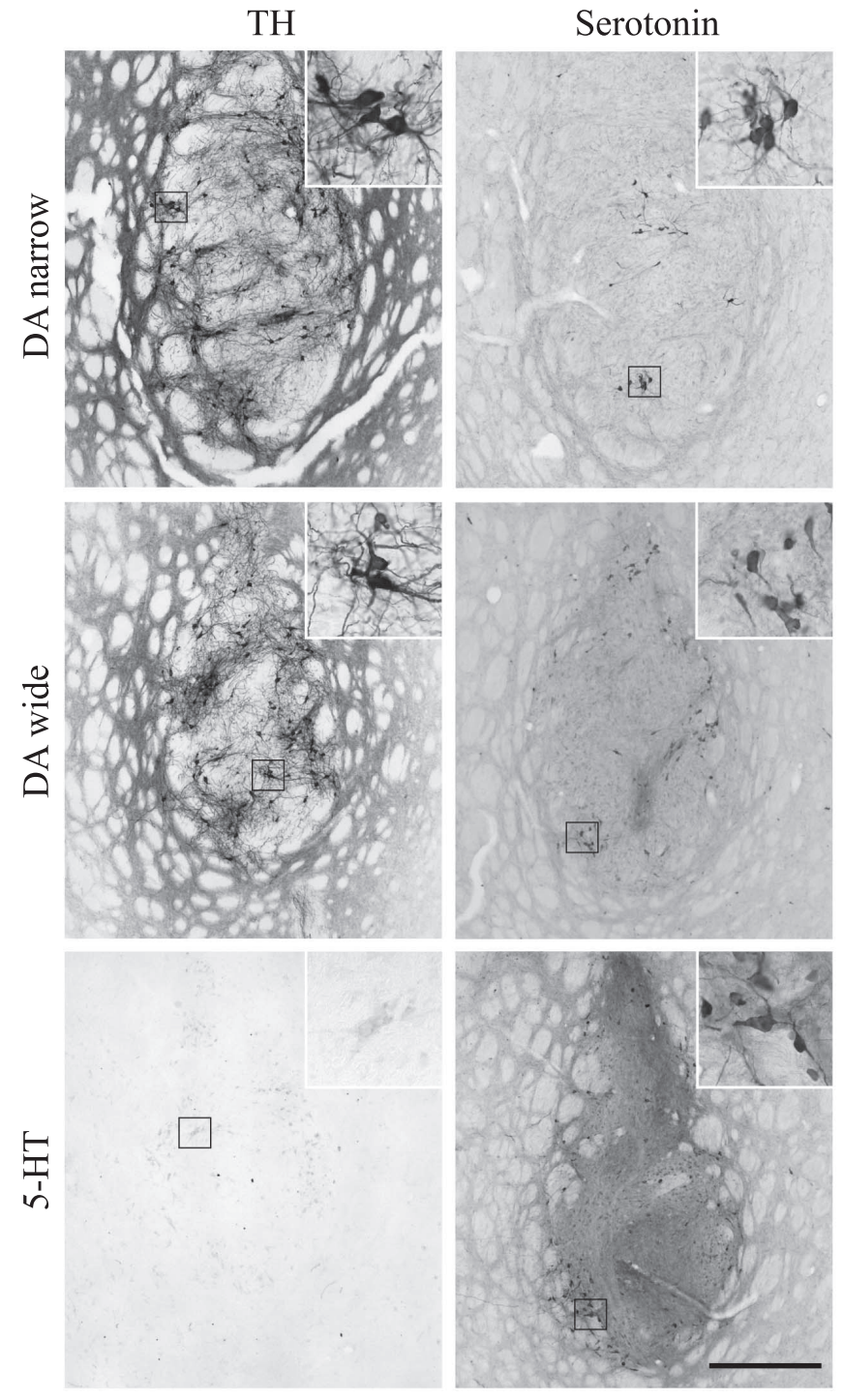

Figure 2. Graft histology. Immunostaining for $\mathrm{TH}(\boldsymbol{A}, \boldsymbol{C}, \boldsymbol{E})$ and serotonin $(\boldsymbol{B}, \boldsymbol{D}, \boldsymbol{F})$ revealed surviving cells in all grafted animals included in the study. The DA-narrow $(\boldsymbol{A})$ and DA-wide $(\boldsymbol{C})$ grafts contained large numbers of TH-positive neurons. In the 5-HT grafts group, in contrast, no or only scattered TH-positive neurons were detectable (E). The 5-HT grafts and the DA-wide grafts contained large numbers of serotonin-positive neurons, which were located both in the vicinity and the center of the graft core $(\boldsymbol{D}, \boldsymbol{F})$. The DA-narrow grafts, in contrast, showed significantly lower numbers of serotonin-positive neurons located mainly in the center of the graft core $(\boldsymbol{B})$. High-power views showing single cells are illustrated as insets in each panel. Scale bar: (in $\boldsymbol{F}) \boldsymbol{A}-\boldsymbol{F}$, low-power photomicrographs, $500 \mu \mathrm{m}$; insets, $125 \mu \mathrm{m}$.

there were $3940 \pm 616$ serotonin cells with only single THpositive neurons (Fig. $3 A, C$ ). In the DA-wide grafts, there were $4390 \pm 640 \mathrm{TH}$-positive and $2443 \pm 291$ serotonin-positive cells constituting a ratio of $\sim 2: 1$ for DA and serotonin neurons, respectively (Fig. $3 A, C$ ). In the sham-operated groups [Les-Ctrl (L-DOPA) and Les-Ctrl (Drug-Naive)], no signs of either TH- or serotonin-positive cells were observed in the striatum at any level.

The TH- and SERT-positive fiber densities were evaluated at seven coronal sections in the striatum (750 $\mu \mathrm{m}$ apart), which covered the entire head and tail of the striatum. In addition, subregional analysis was performed for the $\mathrm{Rdl}$ and the $\mathrm{Cl}$ regions (outlined as shown in Figs. $4 A$ and $5 A$ ). TH immunostaining revealed severe loss of DA neurons (data not shown) and an almost complete denervation of the striatum in all animals in the two lesion control groups [Les-Ctrl (L-DOPA) and Les-Ctrl
A No of graft-derived TH-positive neurons

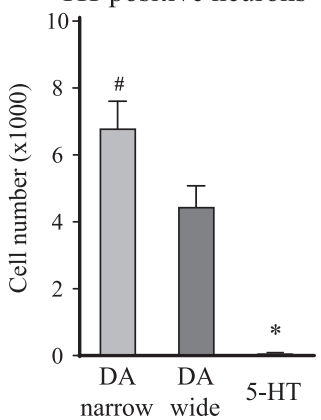

B TH-positive optical density

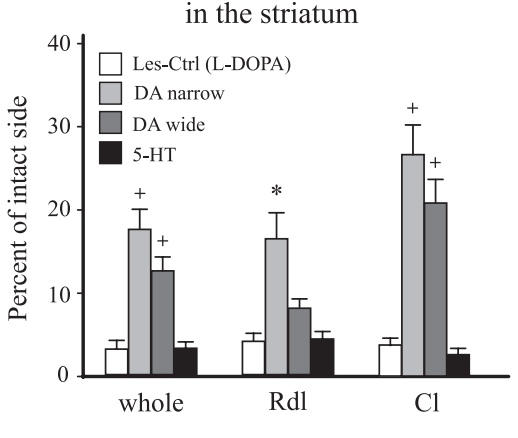

C No of graft-derived serotonin-positive neurons
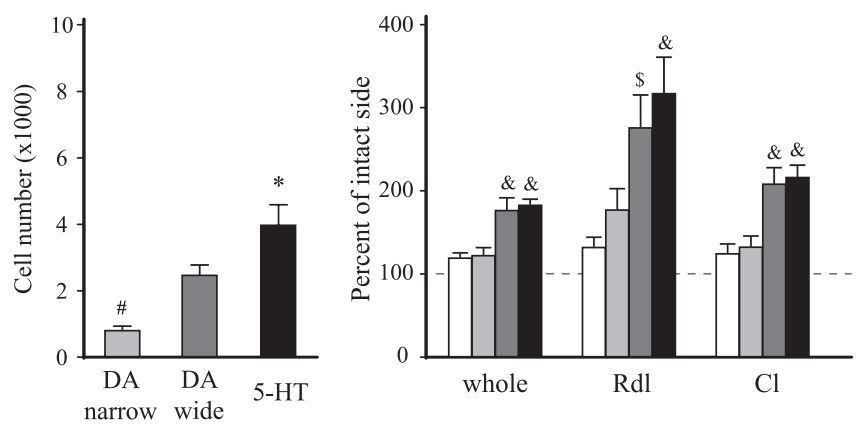

Figure 3. The total number of TH- and serotonin-positive cell numbers, and TH- and SERTpositive fiber density in the striatum. The cell numbers were determined using stereology (optical fractionator), and fiber innervation was assessed by optical density measurements. Fiber densities were measured in the whole striatum (excluding the graft core) and in two separate areas corresponding to the $\mathrm{Rdl}$ and $\mathrm{Cl}$ regions of the head of the striatum (indicated in Figs. $4 A$ and $5 A$ ). The L-DOPA-treated lesion control group [Les-Ctrl (L-DOPA)] showed no TH- or serotonin-positive cells in the striatum at any level, and the TH-positive fiber innervation showed $>95 \%$ depletion, in all regions, after the 6-0HDA lesion (B). The serotonin fiber density analysis, in addition, showed no significant hyperinnervations or hypoinnervations in any of the regions analyzed ( $118-127 \%$ of intact side) $(\boldsymbol{D})$. The DA-narrow grafts contained significantly larger numbers of DA neurons than the DA-wide grafts (6732 \pm 837 vs $4390 \pm 640$, respectively) $(\boldsymbol{A})$. This was matched by an extensive TH-positive fiber innervation in the whole striatum and in the Cl region (DA narrow: whole, $18.2 \pm 2.5 \%$; Cl, 26.6 $\pm 3.6 \%$; DA wide: whole, $13.0 \pm 1.7 \% ; \mathrm{Cl}, 20.8 \pm 2.8 \%$, relative to the intact side) $(\boldsymbol{B})$. The DA-narrow grafts also showed a significant reinnervation of the Rdl region (16.3 $\pm 3.1 \%$ of intact side), which was more pronounced than in the animals with DA-wide grafts ( $8.0 \pm 1.0 \%$ of intact side). The 5 -HT grafts displayed only scattered TH-positive neurons $(7 \pm 2)$, and no significant TH-positive fiber outgrowth in the striatum at any level ( $<5 \%$ of intact side in all regions) $(\boldsymbol{A}, \boldsymbol{B})$. The 5 - $\mathrm{HT}$ graft group showed significantly larger numbers of serotonin-positive neurons in the graft (3865 \pm 605 ) compared with both the DA-wide (2397 \pm 286$)$ and the DA-narrow grafts $(767 \pm 106)$, and the DA-narrow grafts showed significantly lower number of serotonin-positive neurons compared with the DA-wide grafted animals (C). SERT staining revealed a significant graftderived serotonin innervation in the whole striatum in both the $5-\mathrm{HT}(181.9 \pm 14.3 \%$ of intact side) and DA wide (175.6 $\pm 15.4 \%$ of intact side) graft groups. The increase in SERT fiber density was evident in both the Cl region (5-HT, 208.9 \pm 15.6 ; DA wide, $201.1 \pm 20.3 \%$, relative to the intact side) and, in particular, in the Rdl region (5-HT, $306.7 \pm 42.4$; DA wide, $266.7 \pm 37.9 \%$ of intact side) (D). The DA-narrow grafts showed no significant graft-derived serotonin innervation in any region of the host striatum (whole, $121.4 \pm 9.8 \%$; $\mathrm{Rdl}, 170.9 \pm 25.3 \%$; Cl, $127.7 \pm 13.3 \%$, compared with intact side) $(\boldsymbol{D})$. The dashed line in $\boldsymbol{D}$ represents the level of SERT-positive optical density on the contralateral intact side. *Different from all other groups.

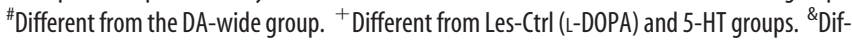
ferent from Les-Ctrl (L-DOPA) and DA-narrow groups. ${ }^{5}$ Different from Les-Ctrl (L-DOPA) group. $A, C$, One-way ANOVAs, $F_{(2,29)}=31.49$ and 14.39 , respectively; $p<0.0001$ for both comparisons. $\boldsymbol{B}$, One-way ANOVAs, $F_{(3,39)}=20.44,10.99$, and 26.66 for whole, $\mathrm{Rdl}$, Cl, respectively; $p<$ 0.0001 for all comparisons. D, One-way ANOVAs, $F_{(3,39)}=8.04,6.82$, and 9.46 for whole, $\mathrm{Rdl}, \mathrm{Cl}$, respectively; $p<0.001$ for all comparisons. All ANOVAs were followed by Tukey's HSD post hoc test.Error bars indicate SEM. 
(Drug-Naive)] (Fig. 4A). Optical density readings showed a $97 \%$ reduction in $\mathrm{TH}$ positive fiber innervation in both whole striatum and the two subregions [Figs. $3 B$ and $4 A$ as shown for Les-Ctrl (L-DOPA) group]. The total $\mathrm{TH}$-positive fiber innervation was increased to $18.2 \pm 1.1$ and $13.0 \pm 1.7 \%$ of normal in the DA-narrow and DA-wide groups, respectively. Subregional analysis indicated that the innervation density in the $\mathrm{Cl}$ region was higher, $26.6 \pm 3.6$ and $20.8 \pm 2.8 \%$, respectively, whereas the innervation in the Rdl region was less pronounced (Figs. $3 B, 4 B, C$ ). Because the 5-HT group contained only scattered DA cells, there was no detectable TH-positive fiber outgrowth in the striatum in any region (Figs. 3B, 4D).

In the SERT-stained sections, the intrinsic serotonin fiber innervation showed a dorsoventral gradient in density, with the most prominent fiber staining in the ventral pallidum and olfactory tubercle (Fig. 5). No significant hyperinnervation was detected on the lesioned side in the two control groups in any region (Figs. 3D, $5 A$ ). In all grafted groups, there was an increase in SERT-positive fibers. The innervation was most extensive in the DA-wide and the 5 -HT groups (Figs. $3 D, 5 C, D$ ). In the DA-narrow group, the graft-derived innervation was sparse and mostly limited to innervation in the $\mathrm{Rdl}$ region of the striatum (Figs. 3D, 5B, inset). On the other hand, the optical density measurements revealed a significant increase in SERTpositive innervation in the whole striatum to $175.6 \pm 15.4$ and $181.9 \pm 14.3 \%$ of control side values in the DA-wide and the 5-HT groups, respectively. In the Rdl region, the SERT innervation density reached to $266.7 \pm 37.9$ and $306.6 \pm$ $42.4 \%$, respectively, suggesting that the SERT-positive fibers grew preferentially toward the rostral part of the striatum.

\section{Drug-induced functional recovery}

Survival and function of the DA-rich grafts were evaluated at 8 weeks after transplantation by amphetamine-induced rotation. In the pretransplantation test, all groups displayed strong rotational bias toward the lesion side (group averages ranging from $9.1 \pm 1.1$ to $10.4 \pm 1.4$ turns per minute) (Fig. 6A). In the 8 week posttransplantation test, the DA-narrow graft group and the DA-wide graft group showed a complete reversal and overcompensation in the rotation test. In contrast, no significant improvement was seen in the 5-HT group, and the rotational response at this time point was not different from the Les-Ctrl (L-DOPA) or the LesCtrl (Drug-Naive) groups $(20.1 \pm 1.6,18.3 \pm 2.1$, and $19.4 \pm 2.8$ turns per minute, respectively) (Fig. 6A). One animal in the DA-

B DA narrow

C DA wide

D $5-\mathrm{HT}$
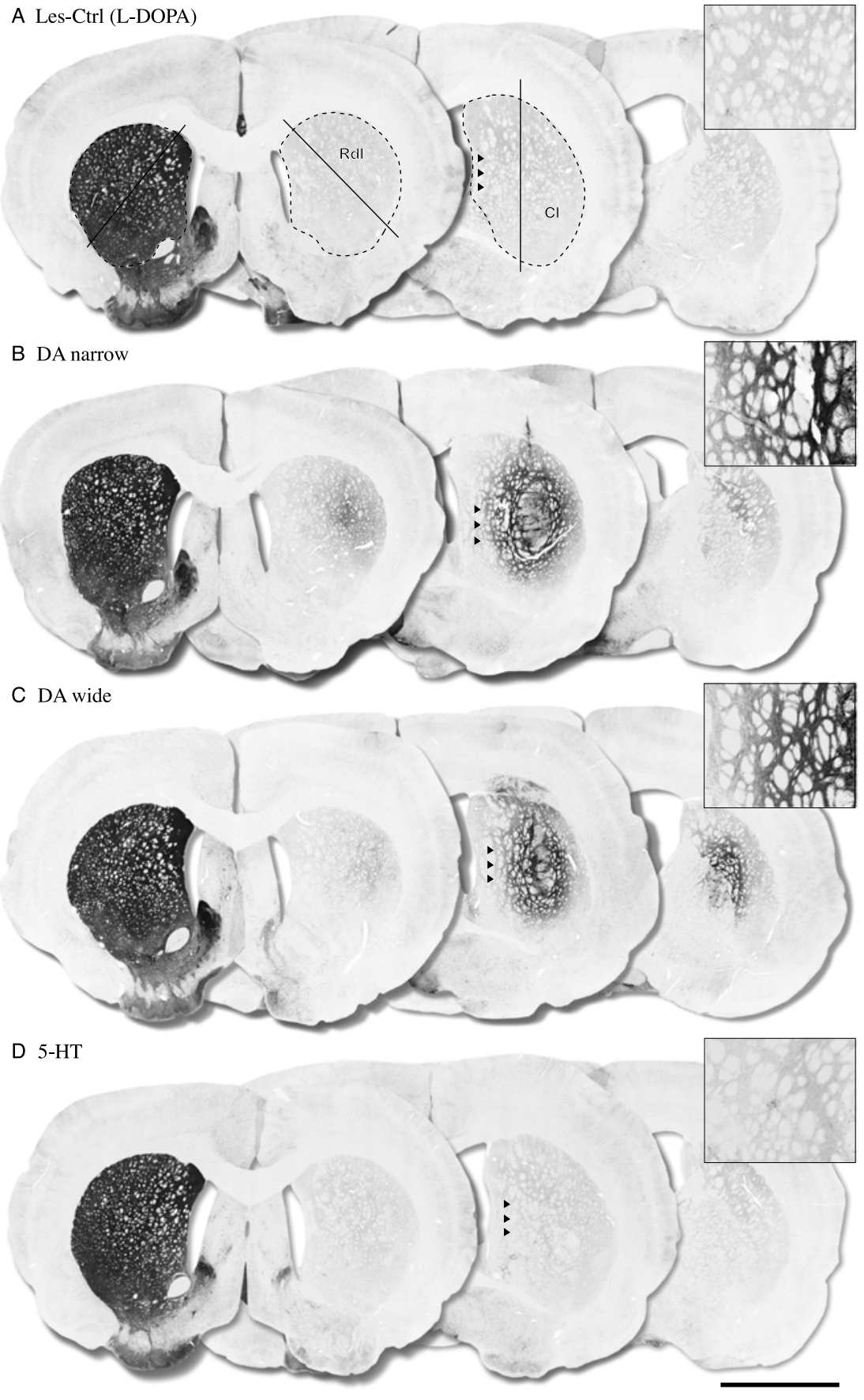

Figure 4. TH-positive immunohistochemistry. The TH-positive fiber outgrowth was measured in the whole striatum and in two selected regions in the head of the striatum, the $\mathrm{Rdl}$, and $\mathrm{Cl}$ as shown in $\boldsymbol{A}$. The lesion control groups showed an almost complete loss of TH-positive fibers throughout the striatum with $>90 \%$ denervation compared with the intact side (A) [Les-Ctrl (Drug-Naive) data not shown]. The groups receiving DA neuron-containing grafts (DA narrow and DA wide) showed significant THpositive fiber innervations in the Cl region ( 40 and $30 \%$ of intact side, respectively) $(B, C)$ and in the whole striatum (19 and $15 \%$ of intact side, respectively) (B,C. The DA-narrow grafts also displayed a significant increase in TH fiber density in the Rdl region (15\% of intact side), which was not observed in the DA-wide group ( $8 \%$ of intact side) ( $\boldsymbol{B}, \boldsymbol{C}$ ). The 5-HT graft group, in contrast, showed no TH-positive fiber outgrowth in the striatum in any region ( $<5 \%$ of intact side) compared with the control groups $(\boldsymbol{D})$. The optical density values presented in brackets represent the animal from which the pictures are taken. Scale bar: (in $\boldsymbol{D}) \boldsymbol{A}-\boldsymbol{D}, 3 \mathrm{~mm}$.

narrow group showed no recovery in the posttransplantation test (26.8 turns per minute) and was excluded from the study. Immunohistochemistry, performed at the end of the study, revealed a small surviving graft including only few $\mathrm{TH}$-positive or serotonin-positive cells ( $<200$ cells for both cell types). 
A Les-Ctrl (L-DOPA)

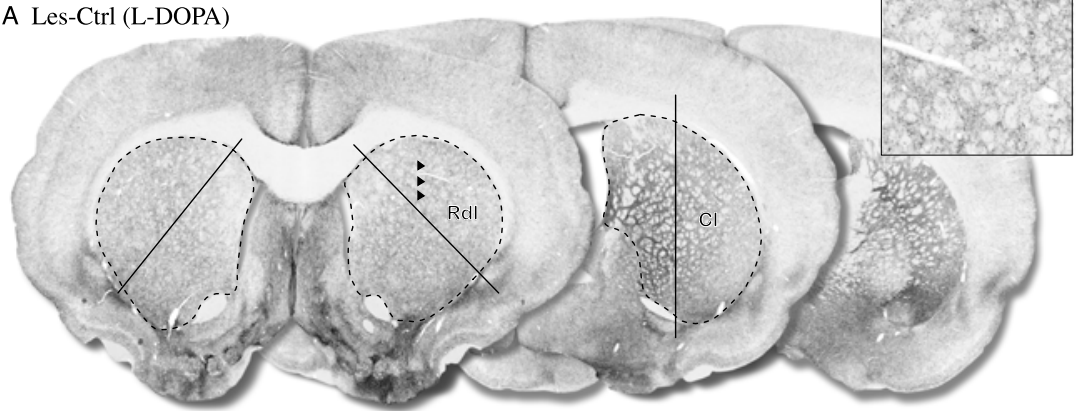

B DA narrow

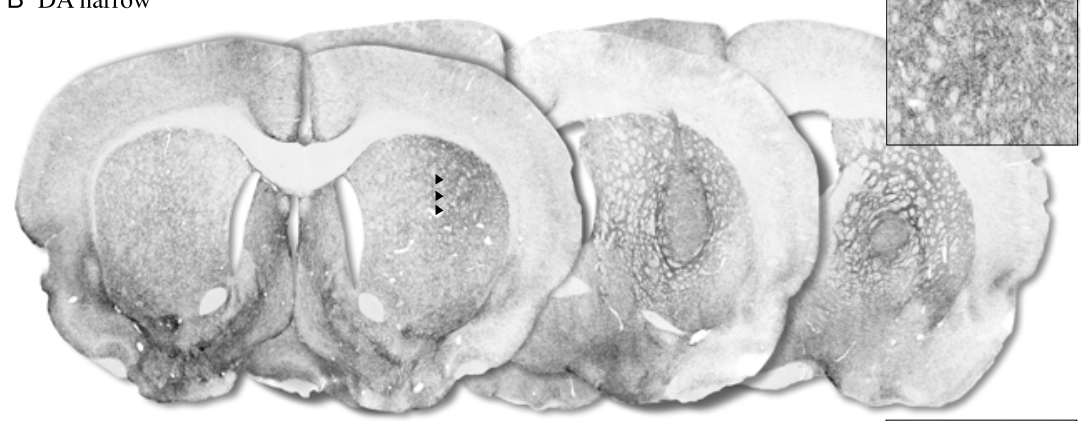

C DA wide

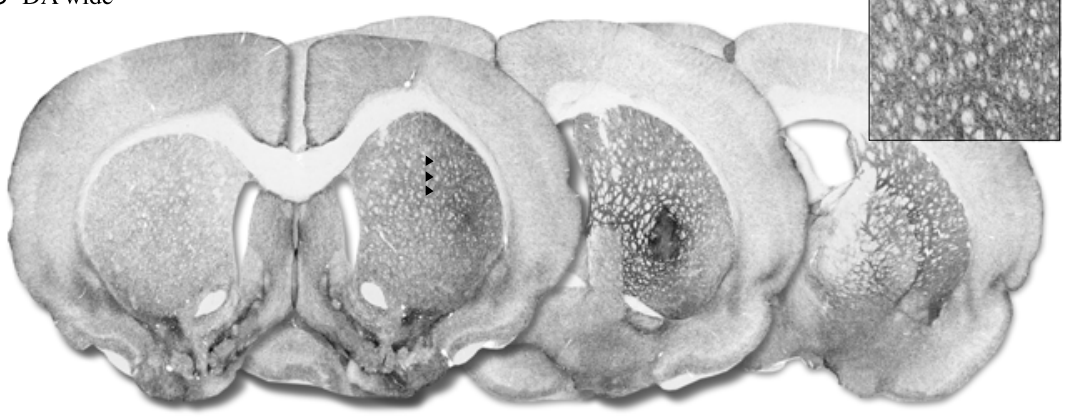

D 5-HT

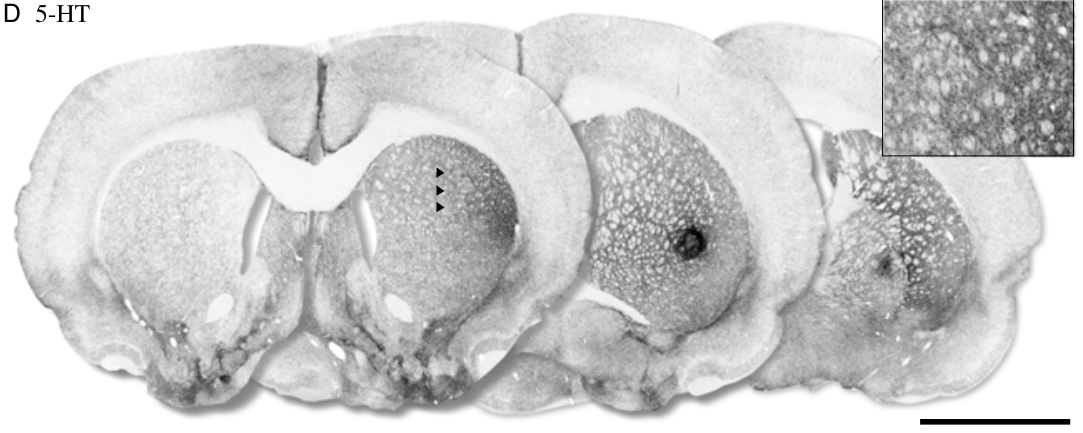

Figure 5. SERT-positive immunohistochemistry. The SERT-positive fiber outgrowth was measured in the whole striatum and in two selected regions in the head of the striatum, the $\mathrm{Rdl}$, and the $\mathrm{Cl}$, as shown in $A$. The lesion control groups showed no significant overall hyperinnervation or hypoinnervation in any of the regions measured (whole, $115 \%$; Rdl, $111 \%$; $\mathrm{Cl}, 110 \%$, compared with intact side) (A) [Les-Ctrl (Drug-Naive) data not shown]. The 5-HT group showed a significant graft-derived SERT-positive fiber outgrowth in whole striatum (205\% of intact side) (D), in the Cl region (218\% of intact side) (D), and, in particular, in the Rdl area (353\% of intact side) (D). The DA-wide graft animals showed similar SERT-positive fiber innervations in the whole striatum and the $\mathrm{Cl}$ region (156 and 168\%, respectively) including the Rdl region (262\% of intact side) (C). The DA-narrow grafts, in contrast, showed no significant graft-derived SERT-positive fiber innervation in either the whole striatum, or in the Rdl and CI regions $(90,150$, and $97 \%$ of intact side, respectively). The optical density values presented in brackets represent the animal from which the pictures are taken. Scale bar: (in $\boldsymbol{D}) \boldsymbol{A}-\boldsymbol{D}, 3 \mathrm{~mm}$.

\section{Spontaneous forelimb use in the cylinder test}

The rats' ability to use the forelimbs during exploration was assessed in the cylinder test at 3 weeks before and at 22 weeks after the transplantation surgery. At 3 weeks after lesion, all animals displayed impairment in the use of the left forepaw, group aver- ages ranging from $12.9 \pm 3.8$ to $19.1 \pm 3.9 \%$ of total touches. At 22 weeks after transplantation, the lesion control groups continued to exhibited severe impairment in the forelimb use [Les-Ctrl (L-DOPA), $4.0 \pm 1.8 \%$; Les-Ctrl (Drug-Naive), $2.5 \pm 2.5 \%$ left paw use]. The 5-HT graft group $(1.3 \pm 1.3 \%)$ and the DA-wide graft group $(4.6 \pm 1.3 \%)$ did not show any improvement. The DA-narrow graft group, in contrast, showed a significantly better performance in the postgrafting test $(30.2 \pm 5.4 \%$ left paw use), compared with all of the other groups. The performance in the cylinder test at 22 weeks was significantly correlated with the TH-positive fiber innervation density in the Rdl region of the striatum $\left(F_{(1,17)}=26.86\right.$, adjusted $r=$ $0.78, p<0.0001$, for DA-narrow and DAwide groups; $F_{(1,27)}=52.20$, adjusted $r=$ $0.81, p<0.0001$, for all three graft groups) (Fig. 6B). SERT fiber innervation in this region correlated less well with cylinder test results $\left(F_{(1,17)}=5.29\right.$, adjusted $r=0.48, p<$ 0.05 , for DA-narrow and DA-wide groups; $F_{(1,27)}=8.97$, adjusted $r=0.45, p<0.01$, for all three graft groups) (data not shown).

\section{Modulation of L-DOPA-induced dyskinesia by intrastriatal VM grafts}

Stable baseline dyskinesias, equivalent to peak dose dyskinesias seen in PD patients, were induced by daily injections of $6 \mathrm{mg} / \mathrm{kg}$ L-DOPA (in combination with $15 \mathrm{mg} / \mathrm{kg}$ benserazide) over $28 \mathrm{~d}$. At the end of this induction phase, the dyskinesias present involved prominent hyperkinetic movements in the forelimb and orolingual muscles and dystonic twisting of the trunk, with an onset at $\sim 10-20 \mathrm{~min}$, a peak at $45-90 \mathrm{~min}$, and return to baseline after $\sim 120-160$ min after drug injection.

AIM tests were performed at 2, 4, 6, 10, 13 , and 16 weeks after the grafting after injection of $6 \mathrm{mg} / \mathrm{kg}$ L-DOPA to evaluate the effect of the different grafts. The Les-Ctrl (DrugNaive) group received injection of saline (vehicle) and, as expected, did not display any signs of abnormal movements. The Les-Ctrl (L-DOPA) group exhibited moderate-tosevere AIM scores throughout the 16 week observation period (Fig. 7A). The DA-wide and the DA-narrow groups reduced total AIMs (a combined score of axial, limb, and orolingual dyskinesias) to 41 and $44 \%$ of pretransplantation values, respectively [corresponding to 69 and $67 \%$ of the Les-Ctrl (LDOPA) group] (Fig. 7A). The total integrated AIM scores in the 5-HT group increased from $716 \pm 58$ at pre- to $1238 \pm 28$ at 16 weeks, representing a $73 \%$ increase from pretransplantation scores and a $30 \%$ increase above the control group at that time point (Fig. 7A). The increase in dyskinesias was attributable to an enhancement of the maximum level of AIMs seen at the peak time, as well as a pro- 
longed duration (Fig. 7B). This observation was further strengthened by a test performed at 18 weeks after injection, at the 3 $\mathrm{mg} / \mathrm{kg}$ L-DOPA dose, at which the dyskinesia aggravating effect of 5-HT grafts were even more clearcut (Fig. 7C). Additional investigation of the individual components of the dyskinesias at 16 weeks indicated that the forelimb and orolingual dyskinesias (constituting the hyperkinetic components) were increased to $152 \%$ of their pregraft value, whereas the axial (dystonic) component was increased up to $220 \%$ (Fig. $7 D, E$ ). In contrast, both the hyperkinetic and dystonic components of the dyskinesias were decreased in the DA-wide and DA-narrow graft groups by $\sim 50$ and $75 \%$, respectively.

We recently showed that a combination of $5-\mathrm{HT}_{1 \mathrm{~A}}$ and $5-\mathrm{HT}_{1 \mathrm{~B}}$ receptor agonists can alleviate the activity of the serotonin neurons by activating an autoreceptor feedback mechanism (Carta et al., 2007). Using this paradigm, in the present experiment, the L-DOPA-induced dyskinesias were evaluated after injection of a mixture of the 5- $\mathrm{HT}_{1 \mathrm{~A}}$ receptor agonist, $8-\mathrm{OH}-\mathrm{DPAT}(0.05 \mathrm{mg} / \mathrm{kg})$, and the $5-\mathrm{HT}_{1 \mathrm{~B}}$ receptor agonist, CP-94253 $(1.0 \mathrm{mg} / \mathrm{kg})$. The results showed that L-DOPA-induced dyskinesia was almost completely blocked in all groups, including the 5 -HT graft group (Fig. $7 F$ ), providing additional evidence that the dyskinesia is triggered by excessive release of newly formed DA from the serotonin terminals. The severity of dyskinesias at least partly correlated with the numbers of surviving serotonin neurons in the striatum $(r=0.52$; $p<$ $0.01)$ but did not correlate with SERT-positive fiber density $(r=$ $0.28 ; p=0.07)$.

\section{Role of postsynaptic DA receptor supersensitivity}

To evaluate the role of postsynaptic DA receptors in the induction of L-DOPA-induced dyskinesias, the $\mathrm{D}_{1} / \mathrm{D}_{2}$ receptor agonist apomorphine was used to induce AIMs in the L-DOPA-treated animals. In this case, we found that the total integrated AIM scores induced by $0.05 \mathrm{mg} / \mathrm{kg}$ apomorphine was unaffected by the 5-HT graft and was similar to the Les-Ctrl (L-DOPA) group suggesting that the serotonin grafts were not able to reverse the DA receptor supersensitivity in the striatal neurons (Fig. $8 A$ ). In the DA-wide and DA-narrow groups, however, the dyskinetic behaviors were much less prominent, indicating that these grafts normalized the postsynaptic DA receptor response. To provide a quantitative estimate of DA receptor supersensitivity, we performed a rotation test after apomorphine administration. The results of this test confirmed the observations in the dyskinesia test and showed that the 5-HT graft group retained a high rotational response [equal to the Les-Ctrl (L-DOPA) group], whereas the DA-wide and DA-narrow groups displayed significantly fewer turns (Fig. 8C).

These data suggest that dysregulated DA release from serotonin terminals, and the inability of the serotonin grafts to normal- ize the postsynaptic DA receptor supersensitivity, cooperate to make dyskinesias worse in the serotonin-rich grafts. The behavioral effects of L-DOPA treatment seen in animals with serotonin grafts is the result of a synergistic action in which uncontrolled swings in DA release from the serotonin terminals act on supersensitive DA receptors. In support of this view, we observed that rotation induced by a low dose of L-DOPA ( $3 \mathrm{mg} / \mathrm{kg})$ in the $5-\mathrm{HT}$ graft group $(-21.0 \pm 2.6$ turns per minute) was amplified more than fourfold compared with the Les-Ctrl group $(-4.8 \pm 1.1$ turns per minute) (Fig. $8 \mathrm{D}$ ).

\section{Graft-induced dyskinesias}

Excessive release of DA from grafted VM neurons, evoked by an intraperitoneal injection of amphetamine, has been introduced as a test of graft-induced dyskinesia, mimicking the troublesome side effects seen in grafted patients (Carlsson et al., 2006; Lane et al., 2006) (see Introduction). Here, we administered amphetamine at a dose of $1.5 \mathrm{mg} / \mathrm{kg}$ to provoke release of DA in the grafted animals. This challenge generated AIMs only in animals with DA-rich grafts (the DA-wide and DA-narrow graft groups) (Fig. $8 \mathrm{~B}$ ). All animals tested in the DA-narrow group, and all but one in the DA-wide group (except the animal that had the smallest graft in this group with $\sim 1400 \mathrm{TH}$-positive cells) displayed dyskinetic behaviors similar to the L-DOPA-induced dyskinesias seen in lesioned control rats, including the forelimb, orolingual and axial components. Circular locomotion, away from the lesioned side was also observed in some animals. The Les-Ctrl ( $\mathrm{L}-$ DOPA) group and the 5-HT graft group showed no signs of any abnormal behaviors after amphetamine injection other than rotation toward the lesion side, which is similar to what is seen in lesion-only animals in the rotation test (Fig. $8 B$ ).

\section{Discussion}

The results show that fetal brainstem DA and serotonin neurons survive well after grafting to the DA-denervated striatum and that 
A

L-DOPA-induced dyskinesia (Limb+Orolingual+Axial)

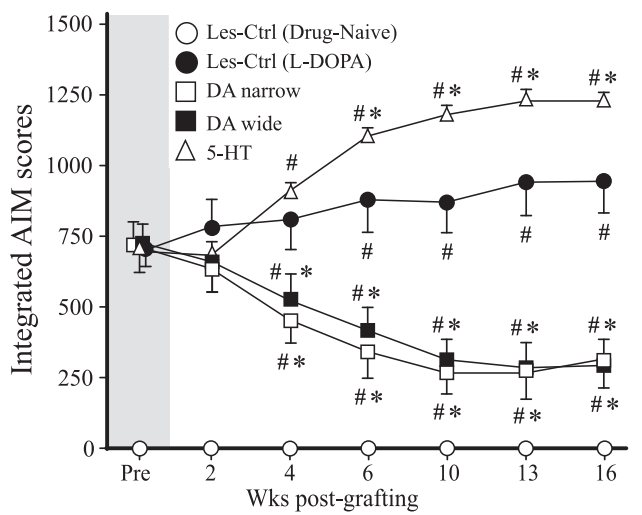

B L-DOPA-induced dyskinesia (Limb+Orolingual+Axial)

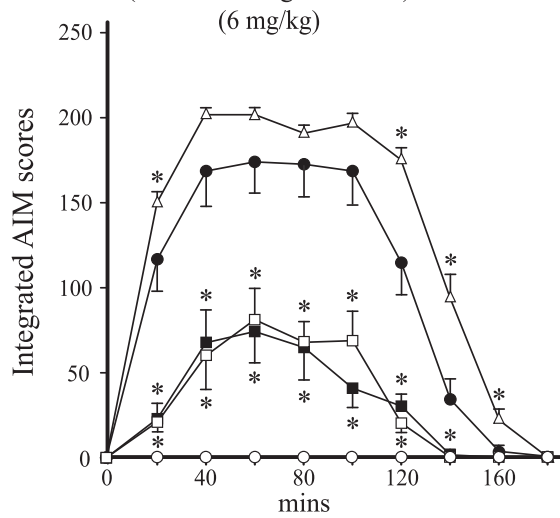

C L-DOPA-induced dyskinesia (Limb+Orolingual+Axial)

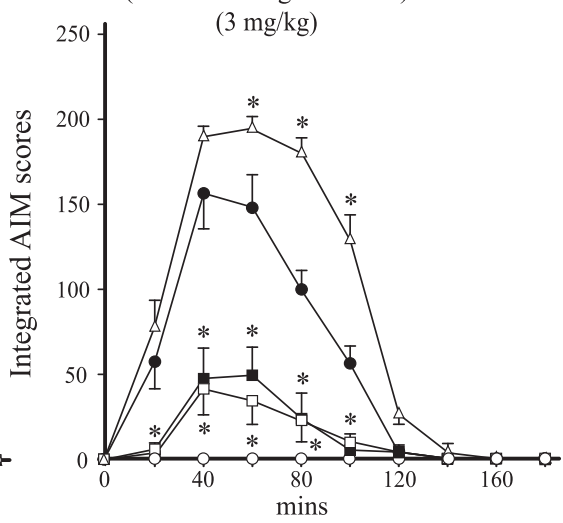
D L-DOPA-induced dyskinesia

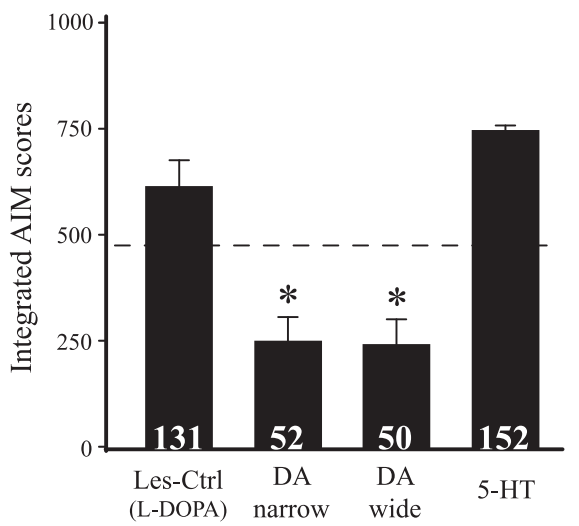

E

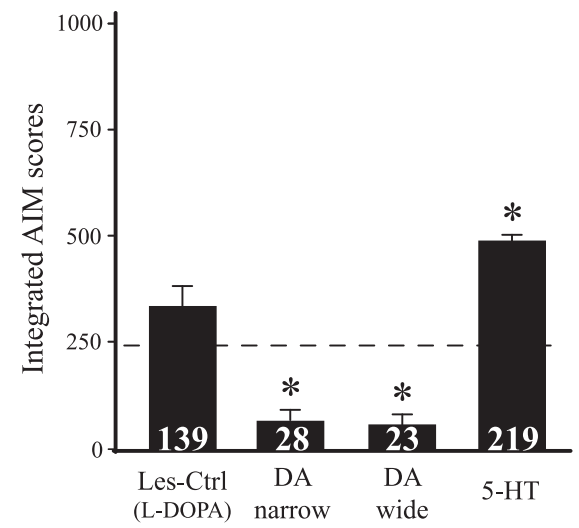

F L-DOPA-induced dyskinesia (Limb+Orolingual+Axial)

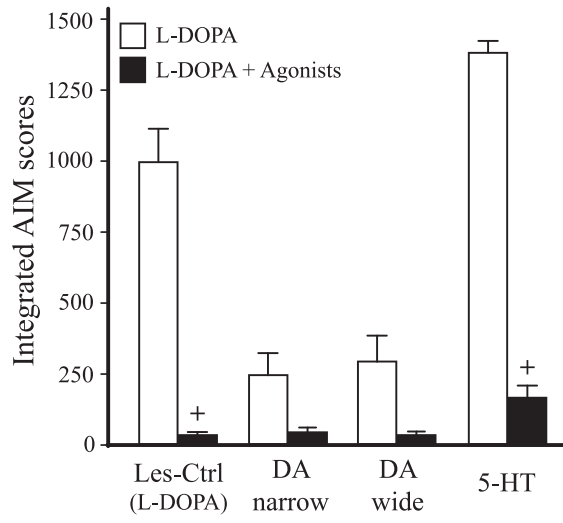

Figure 7. L-DOPA-induced dyskinesia. Dyskinesias induced by L-DOPA (6 mg/kg) were evaluated over 16 weeks after transplantation surgery $(\boldsymbol{A})$. The DA graft groups (DA wide and DA narrow) displayed at progressive reduction in L-DOPA-induced dyskinesia compared with the Les-Ctrl (L-DOPA) group, which became significant at 4 weeks and reached a maximum of $67-69 \%$ reduction at 13-16 weeks after transplantation, compared with the control group. In the 5-HT graft group, in contrast, the dyskinesias increased in magnitude and severity over time. This was first observed at 4 weeks after transplantation and reached a plateau at $10-16$ weeks ( $A$, open triangles). In the DA-narrow and DA-wide groups, the overall reduction in limb, orolingual and axial dyskinesias at 16 weeks, compared with their pretransplantation score, amounted to -56 and $-59 \%$ for the DA-narrow and DA-wide groups, respectively, and a $73 \%$ increase in the 5 -HT graft group. The time course of changes in the integrated AIM scores after a single dose of 6 or $3 \mathrm{mg} / \mathrm{kg} \mathrm{L-DOPA} \mathrm{doses,} \mathrm{a} \mathrm{illustrated} \mathrm{in} B$ and C, revealed a prolongation of the dyskinetic response, and higher peak dyskinesia scores (at $40-80 \mathrm{~min}$ ) in the 5-HT graft group. Analysis of the individual dyskinesia components at 16 weeks revealed a significant increase in the axial component in the 5 -HT graft group, and a significant reduction in both limb plus orolingual and axial components in the $\mathrm{DA}$ groups $(\boldsymbol{D}, \boldsymbol{E})$ (values in brackets represent percentage of pretransplantation values). Treatment with the 5 -HT ${ }_{1 A}$ receptor agonist, 8-OH-DPAT $(0.05 \mathrm{mg} / \mathrm{kg})$, and the 5 - $\mathrm{HT}_{1 \mathrm{~B}}$ receptor agonist, $(\mathrm{P}-94253(1.0 \mathrm{mg} / \mathrm{kg})$, injected $10 \mathrm{~min}$ before L-DOPA $(6 \mathrm{mg} / \mathrm{kg})$, blocked the L-DOPA-induced dyskinesias in all groups, compared with L-DOPA alone $(\boldsymbol{F})$. ${ }^{*}$ Different from Les-Ctrl (L-DOPA) group. "Different from pretransplantation scores. ${ }^{+}$Different from L-DOPA only scores. $A$, Two-way repeated ANOVA, effect of group with individual contrast comparisons, $F_{(3,36)}=15.32$; two-way repeated ANOVA, effect of time with individual contrast comparisons, $F_{(1.9)}=72.45,35.28,39.64$, and 39.64 for Les-Ctrl (L-DOPA), DA narrow, DA wide, and 5-HT, respectively. $B, C$, Two-way repeated ANOVA, effect of group, with individual contrast comparisons $F_{(3,36)}=33.87$ and 43.00 , respectively. $\boldsymbol{D}, \boldsymbol{E}$, One-way ANOVAs, $F_{(3,39)}=44.30$ and 23.24 , respectively. $\boldsymbol{F}$, Two-way factorial ANOVA, $F_{(7,79)}=63.93, p \leq 0.001$ for all comparisons. All ANOVAs were followed by Tukey's HSD test. Error bars indicate SEM.

both types of neurons can grow to form an extensive graftderived terminal network in the host striatum. The functional impact of the two types of grafts, however, was quite different. As expected, the DA neuron-rich grafts induced a marked functional recovery in the 6-OHDA-lesioned animals, as seen in the amphetamine-induced rotation and cylinder tests. This was accompanied by a reduced DA receptor supersensitivity response in the apomorphine-induced rotation test. The DA neuroncontaining grafts induced a significant (56-59\%) reduction of L-DOPA-induced dyskinesia that developed gradually over the first 10 weeks after transplantation. The time course matched well the progressive development of a functional graft-derived DAterminal network in the striatum (Forni et al., 1989; Brundin et al., 1994). None of these effects was seen in the rats that received 5-HT grafts (i.e., grafts containing large numbers of serotonin neurons but no or only single TH-positive cells). Serotonin grafts had no impact on either motor asymmetry in the amphetamineinduced rotation test or spontaneous forelimb use in the cylinder test. These animals, in contrast, showed a progressive worsening of their L-DOPA-induced dyskinesias that was fully developed by 10-13 weeks after grafting (i.e., at the time when the graftderived serotonin innervation is expected to have reached its maximal extent). This worsening was observed as an increase in both the severity and the duration of the dyskinetic response and was seen also at the lowest L-DOPA dose used ( $3 \mathrm{mg} / \mathrm{kg})$.

Based on our previous observations (Carta et al., 2007), we used a combination of a $5-\mathrm{HT}_{1 \mathrm{~A}}$ and a $5-\mathrm{HT}_{1 \mathrm{~B}}$ receptor agonists to block impulse-dependent transmitter release from the serotonergic neurons. At the low doses used here, these drugs act predominantly presynaptically to inhibit serotonergic neuron firing 

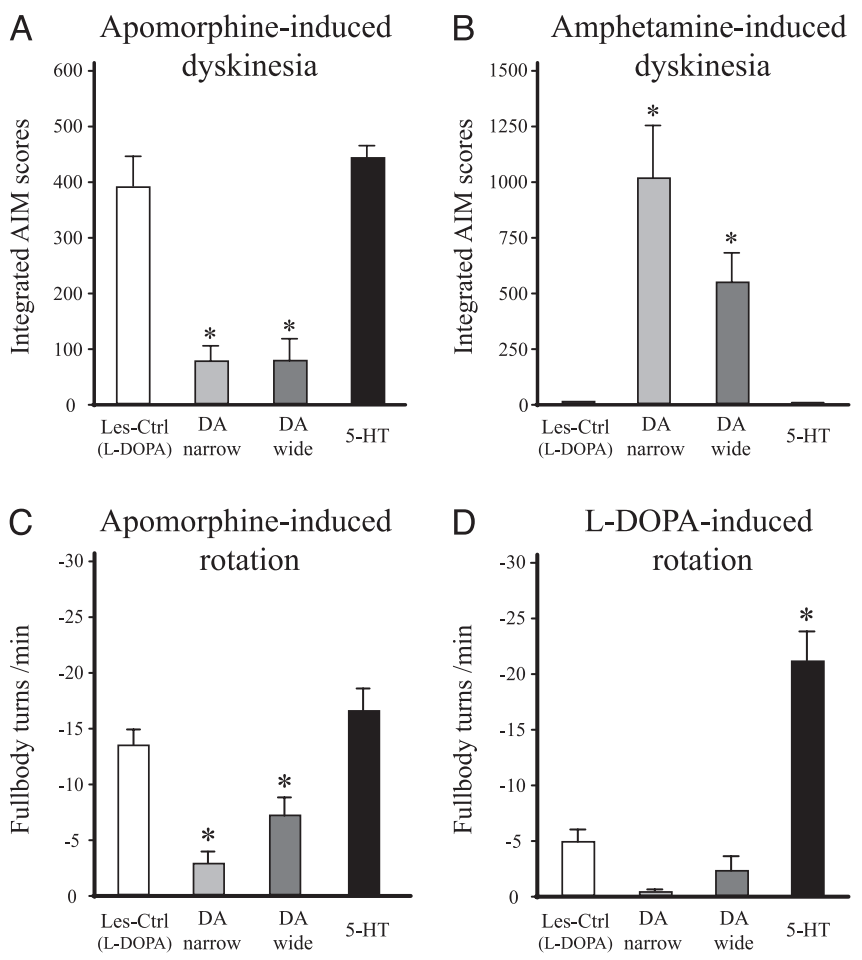

Figure 8. Dyskinesia and rotational behavior induced by direct and indirect DA receptor agonists. $\boldsymbol{A}, \boldsymbol{B}$, Dyskinesias induced by apomorphine $(0.05 \mathrm{mg} / \mathrm{kg})$ and D-amphetamine (1.5 $\mathrm{mg} / \mathrm{kg}$ ) were evaluated at 23 and 27 weeks after transplantation, respectively. Apomorphineinduced dyskinesia $(\boldsymbol{A})$ was reduced by $\sim 80 \%$ in the two DA graft groups (DA wide and DA narrow), compared with the lesion-only controls [Les-Ctrl (L-DOPA)], whereas the 5-HT graft group did not differ from the lesion controls. Dyskinesias induced by amphetamine $(\boldsymbol{B})$ were evident only in the groups receiving DA neuron-containing grafts (DA-wide and DA-narrow graft groups), and not in the 5-HT graft group. C, D, L-DOPA-and apomorphine-induced rotation were evaluated (in automated rotometer bowls) as a measure of postsynaptic striatal DA receptor supersensitivity at 19 and 23 weeks after transplantation, respectively. Rotation induced by either apomorphine $(\boldsymbol{C})$ or L-DOPA $(\boldsymbol{D})$ was significantly reduced in the DA-wide and DA-narrow graft groups, indicating a partial normalization of DA receptor supersensitivity in the animals with DA neuron-containing grafts. In the 5-HT graft group, rotation induced by apomorphine was unaffected, and L-DOPA-induced rotation (at the $3 \mathrm{mg} / \mathrm{kg}$ L-DOPA dose) was markedly increased, compared with the lesion controls. These data indicate that striatal DA receptors remain supersensitive in 5-HT grafts lacking dopaminergic neurons. * Different from Les-Ctrl (L-DOPA). One way ANOVAs, $F_{(3,39)}=27.39$ and 10.41 for $A$ and $B$, respectively; $p<0.001$ for both comparisons followed by Dunnett's post hoc test. One-way ANOVAs, $F_{(3,39)}=36.90$ and 15.43 for $C$ and $D$, respectively; $p<0.001$ for all comparisons followed by Tukey's HSD post hoc test. Error bars indicate SEM.

and, hence, the release of L-DOPA-derived DA from the serotonergic terminals (Sprouse and Aghajanian, 1987; Carey et al., 2004; Bert et al., 2006). In our previous study, we showed that removal of the serotonin innervation, or dampening of serotonin neuron activity by the two agonist drugs, results in a nearcomplete blockade of L-DOPA-induced dyskinesia in 6-OHDAlesioned rats (Carta et al., 2007). Consistent with these data, dyskinesias were reduced by $>80 \%$ in both the 6-OHDA lesion controls and in the grafted animals, suggesting that L-DOPAinduced dyskinesia, at the dose used here $(6 \mathrm{mg} / \mathrm{kg})$, is almost entirely dependent on DA released as a "false transmitter" from the intrinsic or the graft-derived serotonergic terminals. An increased striatal serotonin innervation to levels above normal, as seen in the animals with serotonin neuron-containing grafts, made the L-DOPA-induced dyskinesias even worse.

Interestingly, however, our results indicate that serotonin neurons are detrimental only in the absence of a functional striatal dopaminergic innervation. At low-to-moderate L-DOPA doses, the formation, storage, and impulse-dependent release of L-DOPA-derived DA is likely to take place almost exclusively from dopaminergic and serotonergic axon terminals. In dopaminergic synapses, extracellular DA will be tightly regulated by a combination of DA reuptake (via the membrane transporter, DAT) and $\mathrm{D}_{2}$-autoreceptor-mediated feedback control. These autoregulatory mechanisms are lacking in serotonin neurons. For this reason, DA released from serotonin terminals is likely to generate excessive swings in the extracellular levels of DA in response to systemic L-DOPA administration. These swings may be counteracted, or dampened, by the presence of DA terminals that can provide a capacity for DA reuptake and thus act as buffer for the swings in extracellular DA. In animals with DA-rich transplants, in which DA neurons in the graft provide a dense dopaminergic innervation of the host striatum, the presence of a serotonin innervation, derived from either the grafted serotonin neurons or the intrinsic serotonergic afferents, may provide an additional source of L-DOPA-derived DA that can be taken up by the DA terminals via the DAT. This interplay between the DA and serotonin terminals may explain why the presence of serotonin neurons in the DA-rich transplants, and the DA-wide grafts in particular, did not induce the same worsening of L-DOPAinduced dyskinesia as seen in the 5-HT-only transplants, despite similar levels in serotonin hyperinnervation in both groups. In both the DA-narrow grafts (which contained DA and serotonin neurons in a proportion of $\sim 9: 1$ ) and the DA-wide grafts (in proportion 2:1), $\sim_{\text {L-DOPA-induced dyskinesia was reduced to }}$ the same extent despite that the serotonin innervation of the host striatum was much more prominent in the DA-wide group. Most interestingly, however, the dyskinesia seen in these animals (as in the lesion-only controls) was almost completely eliminated by the 5- $\mathrm{HT}_{1 \mathrm{~A}}$ and $5-\mathrm{HT}_{1 \mathrm{~B}}$ agonist treatment, indicating that this residual level of dyskinesia indeed is maintained by DA released from serotonergic terminals. Because the effect of 5-HT autoreceptor agonist treatment was equally prominent in the nontransplanted 6-OHDA-lesioned rats, it seems likely that the intrinsic serotonin afferents may play an important role in this regard.

The DA and serotonin neuron grafts are different not only in the way they handle and release L-DOPA-derived DA but also in the way they influence postsynaptic DA receptor supersensitivity. In 6-OHDA-lesioned rats, low doses of apomorphine induces active turning, in the direction away from the lesioned side, by acting on supersensitive DA receptors in the DA-denervated striatum. Reinnervation by DA-rich transplants are known to reduce apomorphine-induced turning by up to $70-80 \%$, which is attributable to a normalization of DA receptor supersensitivity by DA released from the graft-derived DA terminals (Bjorklund, 1992; Stromberg et al., 2000). In agreement, apomorphine-induced dyskinesia (i.e., AIMs induced by direct activation of supersensitive postsynaptic receptors) was unaffected by the 5 -HT grafts, but reduced by $\sim 80 \%$ in the two DA-rich graft groups. This points to a second factor of importance in the interaction between DA and 5-HT neurons: in transplants with few or no DA neurons (i.e., transplants that give rise to a limited dopaminergic reinnervation of the host striatum), DA released from serotonin terminals will act on DA receptors that remain supersensitive because of the lack of a functional DA input. In DA-rich grafts, in contrast, DA receptor supersensitivity will be reduced or normalized, which will help to limit the impact of the dysregulated DA release derived from the serotonin afferents.

Although the DA-narrow and DA-wide grafts had similar effects on the L-DOPA and apomorphine-induced dyskinesias, 
their impact on the lesion-induced motor impairments (i.e., their antiparkinsonian effects) were clearly different in magnitude. The DA-narrow grafts induced a significant improvement in forelimb use that was not seen in animals with DAwide grafts, and the reversal of motor asymmetry in the amphetamine- and apomorphine-induced rotation tests was more pronounced in the DA-narrow than the DA-wide group. It is possible that this difference could be attributable to the threefold higher number of serotonin neurons included in the DA-wide grafts. This would imply that the presence of larger numbers of serotonin neurons in the DA-rich grafts may have an inhibitory effect on either the survival, growth, or function of the grafted DA neurons (Rodriguez-Pallares et al., 2003; De Deurwaerdere et al., 2004). It seems more likely, however, that this difference in antiparkinsonian effect is attributable to the fact that the DA-narrow grafts contained $\sim 50 \%$ more DA neurons than the DA-wide grafts, and that the TH-positive fiber innervation from the DA-narrow grafts was more extensive, particularly in the dorsolateral sector of the rostral striatum, which is a prime site for the regulation of motor asymmetry and turning behavior (Dunnett et al., 1981, 1983; Mandel et al., 1990). As discussed in our earlier study (Carlsson et al., 2006), the antidyskinetic effect of DA-rich grafts is most probably dependent on reinnervation of a more caudallateral sector of the host striatum (i.e., the area of the head of the striatum that is known to be involved in the induction of stereotypic forelimb and orolingual movements) (Kelley et al., 1988; Brown and Sharp, 1995; Canales et al., 2000). This area was relatively well innervated from both DA-narrow and DAwide grafts in the present study.

The present results show that grafts containing serotonin neurons can have a detrimental effect on L-DOPA-induced dyskinesia but that their impact will depend on the presence or absence of DA neurons in the graft. In grafts with few or no DA cells, the serotonin neurons induced a marked increase in both the magnitude and duration of dyskinesia in response to a single L-DOPA dose. In animals with DA-rich grafts, in contrast, L-DOPA-induced dyskinesias were markedly reduced regardless of the number of serotonin neurons present in the grafts. This suggests an important interplay between the dopaminergic and serotonergic terminals in the host striatum. In the absence of a functional DA innervation, DA formed from L-DOPA and released, as a false transmitter, from the serotonin terminals will result in excessive swings in extracellular $\mathrm{DA}$, inducing dyskinesia. This scenario is most likely in areas with no or sparse DA innervation but rich serotonin innervation resulting in release primarily from serotonin terminals. In this case, the dopamine receptors will remain supersensitive. It seems plausible that release of DA from the graft-derived terminals at receptor sites that remain supersensitive can elicit abnormal behavioral responses, as seen here in the 5-HT group after administration of L-DOPA, or triggered in the DA-grafted animals by DA release induced by amphetamine [the latter studied in additional detail by Carlsson et al. (2006) and Lane et al. (2006)]. This mechanism may also explain the appearance of off-state dyskinesias in some of the grafted patients. In the presence of a functional DA innervation, derived from the graft or from spared DA afferents, the swings in extracellular DA released from serotonin terminals are counteracted by an active reuptake of DA from the extracellular space by the DA terminals. Desensitization of the supersensitive postsynaptic DA receptors by DA released from the dopaminergic terminals will further add to this antidyskinetic ef- fect. This interaction between serotonin and DA terminals may explain why in previous clinical trials the effect of DArich fetal VM transplants on peak dose dyskinesias has been so variable.

In conclusion, we propose that, in patients with grafts that contain large numbers of serotonin neurons, peak dose dyskinesia may be unaffected or may even get worse. This would be the case if the graft contain a low number of DA neurons, or if the graft-derived DA innervation does not cover the critical, dyskinesia-inducing parts of the host putamen leaving the subject vulnerable to DA swings that may be induced by serotonin terminals. Conversely, L-DOPA-induced dyskinesia would be expected to decline over time in patients with DArich grafts, provided that the associated DA fiber outgrowth is covering large areas of the putamen. Thus, inclusion of serotonin neurons in the graft may not have any major detrimental effects in those cases in which the grafts contain large numbers of DA neurons, in combination with an extensive DA reinnervation of the host putamen. However, in cases in which there is no or limited DA innervation of the striatum, the serotonin neurons are likely to exacerbate L-DOPA-induced dyskinesias, or induce off-state dyskinesias, in the grafted patients. Therefore, in future clinical trials, it would be advisable to secure that the graft cell preparations contain as few serotonin neurons as possible.

\section{References}

Arai R, Karasawa N, Geffard M, Nagatsu T, Nagatsu I (1994) Immunohistochemical evidence that central serotonin neurons produce dopamine from exogenous L-DOPA in the rat, with reference to the involvement of aromatic L-amino acid decarboxylase. Brain Res 667:295-299.

Arai R, Karasawa N, Geffard M, Nagatsu I (1995) L-DOPA is converted to dopamine in serotonergic fibers of the striatum of the rat: a doublelabeling immunofluorescence study. Neurosci Lett 195:195-198.

Bert B, Fink H, Hortnagl H, Veh RW, Davies B, Theuring F, Kusserow H (2006) Mice over-expressing the $5-\mathrm{HT}_{1 \mathrm{~A}}$ receptor in cortex and dentate gyrus display exaggerated locomotor and hypothermic response to 8-OHDPAT. Behav Brain Res 167:328-341.

Bjorklund A (1992) Dopaminergic transplants in experimental parkinsonism: cellular mechanisms of graft-induced functional recovery. Curr Opin Neurobiol 2:683-689.

Brown LL, Sharp FR (1995) Metabolic mapping of rat striatum: somatotopic organization of sensorimotor activity. Brain Res 686:207-222.

Brundin P, Duan WM, Sauer H (1994) Functional effects of mesencephalic dopamine and adrenal chromaffin cells grafted to the rodent striatum. In: Functional neural transplantation (Dunnett SB, Bjorklund A, eds), pp 9-46. New York: Raven.

Brundin P, Pogarell O, Hagell P, Piccini P, Widner H, Schrag A, Kupsch A, Crabb L, Odin P, Gustavii B, Bjorklund A, Brooks DJ, Marsden CD, Oertel WH, Quinn NP, Rehncrona S, Lindvall O (2000) Bilateral caudate and putamen grafts of embryonic mesencephalic tissue treated with lazaroids in Parkinson's disease. Brain 123:1380-1390.

Canales JJ, Gilmour G, Iversen SD (2000) The role of nigral and thalamic output pathways in the expression of oral stereotypies induced by amphetamine injections into the striatum. Brain Res 856:176-183.

Carey RJ, Depalma G, Damianopoulos E, Muller CP, Huston JP (2004) The 5-HT1A receptor and behavioral stimulation in the rat: effects of 8-OHDPAT on spontaneous and cocaine-induced behavior. Psychopharmacology (Berl) 177:46-54.

Carlsson T, Winkler C, Lundblad M, Cenci MA, Bjorklund A, Kirik D (2006) Graft placement and uneven pattern of reinnervation in the striatum is important for development of graft-induced dyskinesia. Neurobiol Dis 21:657-668.

Carta M, Carlsson T, Kirik D, Bjorklund A (2007) Dopamine released from 5-HT terminals is the cause of L-DOPA-induced dyskinesia in parkinsonian rats. Brain 130:1819-1833.

De Deurwaerdere P, Navailles S, Berg KA, Clarke WP, Spampinato U (2004) Constitutive activity of the serotonin $2 \mathrm{C}$ receptor inhibits in vivo dopa- 
mine release in the rat striatum and nucleus accumbens. J Neurosci 24:3235-3241.

Defer GL, Geny C, Ricolfi F, Fenelon G, Monfort JC, Remy P, Villafane G, Jeny R, Samson Y, Keravel Y, Gaston A, Degos JD, Peschanski M, Cesaro P, Nguyen JP (1996) Long-term outcome of unilaterally transplanted parkinsonian patients. I. Clinical approach. Brain 119:41-50.

Dunnett SB, Bjorklund A (1992) Neural transplantation: a practical approach. Oxford: Oxford UP.

Dunnett SB, Bjorklund A, Stenevi U, Iversen SD (1981) Grafts of embryonic substantia nigra reinnervating the ventrolateral striatum ameliorate sensorimotor impairments and akinesia in rats with 6-OHDA lesions of the nigrostriatal pathway. Brain Res 229:209-217.

Dunnett SB, Bjorklund A, Schmidt RH, Stenevi U, Iversen SD (1983) Intracerebral grafting of neuronal cell suspensions. IV. Behavioural recovery in rats with unilateral 6-OHDA lesions following implantation of nigral cell suspensions in different forebrain sites. Acta Physiol Scand Suppl 522:29-37.

Forni C, Brundin P, Strecker RE, el Ganouni S, Bjorklund A, Nieoullon A (1989) Time-course of recovery of dopamine neuron activity during reinnervation of the denervated striatum by fetal mesencephalic grafts as assessed by in vivo voltammetry. Exp Brain Res 76:75-87.

Georgievska B, Carlsson T, Lacar B, Winkler C, Kirik D (2004) Dissociation between short-term increased graft survival and long-term functional improvements in Parkinsonian rats overexpressing glial cell line-derived neurotrophic factor. Eur J Neurosci 20:3121-3130.

Gundersen HJ, Jensen EB (1987) The efficiency of systematic sampling in stereology and its prediction. J Microsc 147:229-263.

Hagell P, Schrag A, Piccini P, Jahanshahi M, Brown R, Rehncrona S, Widner H, Brundin P, Rothwell JC, Odin P, Wenning GK, Morrish P, Gustavii B, Bjorklund A, Brooks DJ, Marsden CD, Quinn NP, Lindvall O (1999) Sequential bilateral transplantation in Parkinson's disease: effects of the second graft. Brain 122:1121-1132.

Hauser RA, Freeman TB, Snow BJ, Nauert M, Gauger L, Kordower JH, Olanow CW (1999) Long-term evaluation of bilateral fetal nigral transplantation in Parkinson disease. Arch Neurol 56:179-187.

Hollister AS, Breese GR, Mueller RA (1979) Role of monoamine neural systems in L-dihydroxyphenylalanine-stimulated activity. J Pharmacol Exp Ther 208:37-43.

Kelley AE, Lang CG, Gauthier AM (1988) Induction of oral stereotypy following amphetamine microinjection into a discrete subregion of the striatum. Psychopharmacology (Berl) 95:556-559.

Kirik D, Winkler C, Bjorklund A (2001) Growth and functional efficacy of intrastriatal nigral transplants depend on the extent of nigrostriatal degeneration. J Neurosci 21:2889-2896.

Lane EL, Winkler C, Brundin P, Cenci MA (2006) The impact of graft size on the development of dyskinesia following intrastriatal grafting of embryonic dopamine neurons in the rat. Neurobiol Dis 22:334-345.

Lee CS, Cenci MA, Schulzer M, Bjorklund A (2000) Embryonic ventral mesencephalic grafts improve levodopa-induced dyskinesia in a rat model of Parkinson's disease. Brain 123:1365-1379.

Lindgren HS, Rylander D, Ohlin KE, Lundblad M, Cenci MA (2007) The "motor complication syndrome" in rats with 6-OHDA lesions treated chronically with L-DOPA: Relation to dose and route of administration. Behav Brain Res 177:150-159.
Maeda T, Nagata K, Yoshida Y, Kannari K (2005) Serotonergic hyperinnervation into the dopaminergic denervated striatum compensates for dopamine conversion from exogenously administered L-DOPA. Brain Res 1046:230-233.

Mandel RJ, Brundin P, Bjorklund A (1990) The importance of graft placement and task complexity for transplant-induced recovery of simple and complex sensorimotor deficits in dopamine denervated rats. Eur J Neurosci 2:888-894.

Ng KY, Chase TN, Colburn RW, Kopin IJ (1970) L-DOPA-induced release of cerebral monoamines. Science 170:76-77.

Ng KY, Colburn RW, Kopin IJ (1971) Effects of L-DOPA on efflux of cerebral monoamines from synaptosomes. Nature 230:331-332.

Nikkhah G, Olsson M, Eberhard J, Bentlage C, Cunningham MG, Bjorklund A (1994) A microtransplantation approach for cell suspension grafting in the rat Parkinson model: a detailed account of the methodology. Neuroscience 63:57-72.

Paxinos G, Watson C (2005) The rat brain in stereotaxic coordinates, Ed 5. San Diego: Academic.

Rodriguez-Pallares J, Guerra MJ, Labandeira-Garcia JL (2003) Elimination of serotonergic cells induces a marked increase in generation of dopaminergic neurons from mesencephalic precursors. Eur J Neurosci 18:2166-2174.

Schallert T, Tillerson J (1999) Intervention strategies for degeneration of dopamine neurons in parkinsonism: optimising behavioral assessment of outcome. In: Innovative models of CNS disease: from molecule to therapy, pp 131-151. Clifton, NJ: Humana.

Sprouse JS, Aghajanian GK (1987) Electrophysiological responses of serotoninergic dorsal raphe neurons to 5-HT1A and 5-HT1B agonists. Synapse 1:3-9.

Stromberg I, Kehr J, Andbjer B, Fuxe K (2000) Fetal ventral mesencephalic grafts functionally reduce the dopamine D2 receptor supersensitivity in partially dopamine reinnervated host striatum. Exp Neurol 164:154-165.

Torres EM, Meldrum A, Kirik D, Dunnett SB (2006) An investigation of the problem of two-layered immunohistochemical staining in paraformaldehyde fixed sections. J Neurosci Methods 158:64-74.

West MJ (1999) Stereological methods for estimating the total number of neurons and synapses: issues of precision and bias. Trends Neurosci 22:51-61.

Widner H, Tetrud J, Rehncrona S, Snow B, Brundin P, Gustavii B, Bjorklund A, Lindvall O, Langston JW (1992) Bilateral fetal mesencephalic grafting in two patients with parkinsonism induced by 1-methyl-4-phenyl1,2,3,6-tetrahydropyridine (MPTP). N Engl J Med 327:1556-1563.

Winkler C, Bentlage C, Nikkhah G, Samii M, Bjorklund A (1999) Intranigral transplants of GABA-rich striatal tissue induce behavioral recovery in the rat Parkinson model and promote the effects obtained by intrastriatal dopaminergic transplants. Exp Neurol 155:165-186.

Winkler C, Kirik D, Bjorklund A, Cenci MA (2002) L-DOPA-induced dyskinesia in the intrastriatal 6-hydroxydopamine model of Parkinson's disease: relation to motor and cellular parameters of nigrostriatal function. Neurobiol Dis 10:165-186.

Winkler C, Kirik D, Bjorklund A (2005) Cell transplantation in Parkinson's disease: how can we make it work? Trends Neurosci 28:86-92. 